\title{
HINTS ON HORSES
}

HOW TO

JUDGE

THEM

BUY

THEM

RIDE

THEM

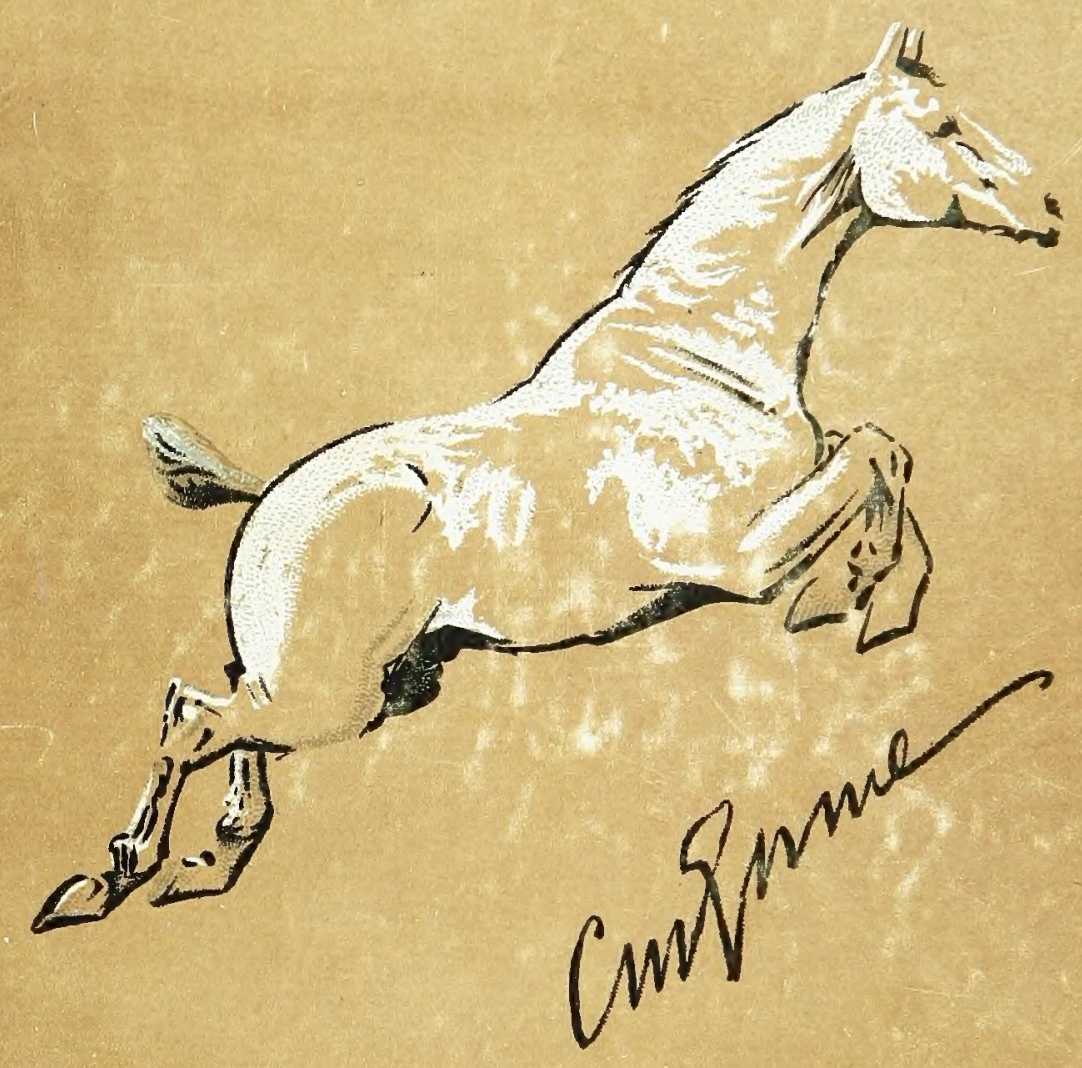

DRIVE THEM AND DEPICT THEM 


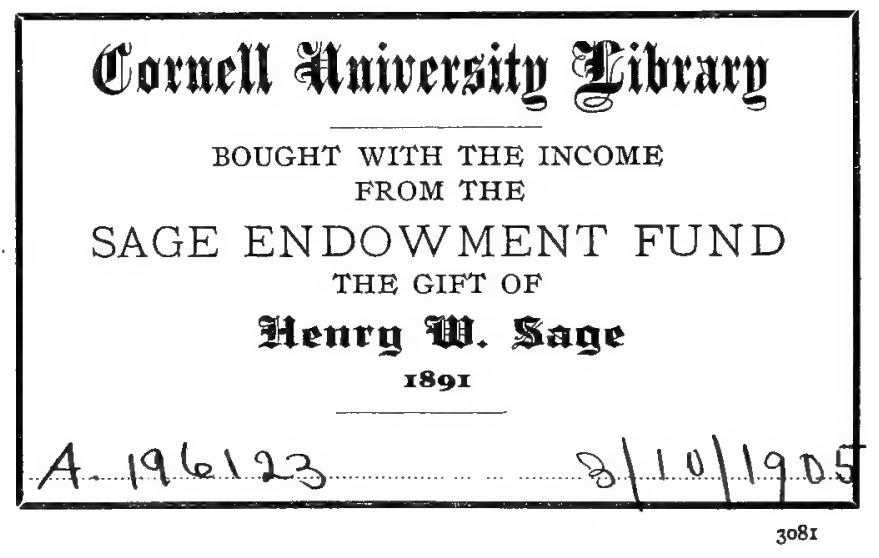

Digitized by Microsoft巴 
3 $1924 \quad 104225440$

Digitized by Microsoft巴 
This book was digitized by Microsoft Corporation in cooperation with Cornell University Libraries, 2007.

You may use and print this copy in limited quantity for your personal purposes, but may not distribute or provide access to it (or modified or partial versions of it) for revenue-generating or other commercial purposes. 


\section{HINTS ON HORSES}


First Edition . . . . . November, I904.

Reprinted . . . . . . . May, 1905. 
Digitized by Microsoft巴 


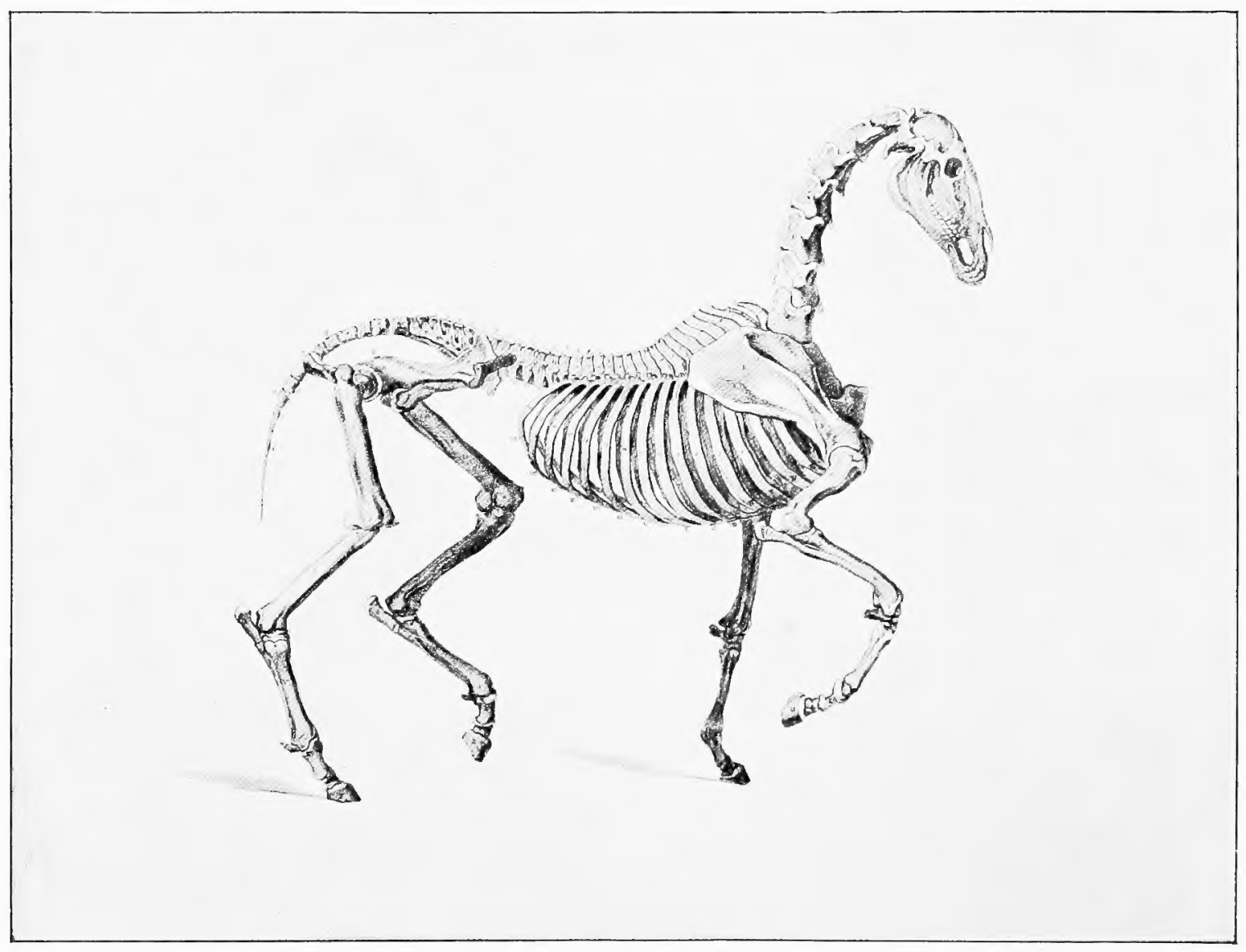

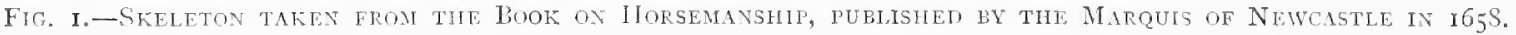


Digitized by Microsoft巴 
Digitized by Microsoft巴 


\title{
HINTS ON HORSES
}

HOW TO JUDGE THEM, BUY THEM, RIDE THEM, DRIVE THEM, AND DEPICT THEM

\author{
BY \\ CAPTAIN C: M. GONNE, R.A.
}

WITH ILLUSTRATIONS

NEW YORK

E. P. DUTTON AND COMPANY

I 905

Digitized by Microsoft巴 


\section{O NTENTS}

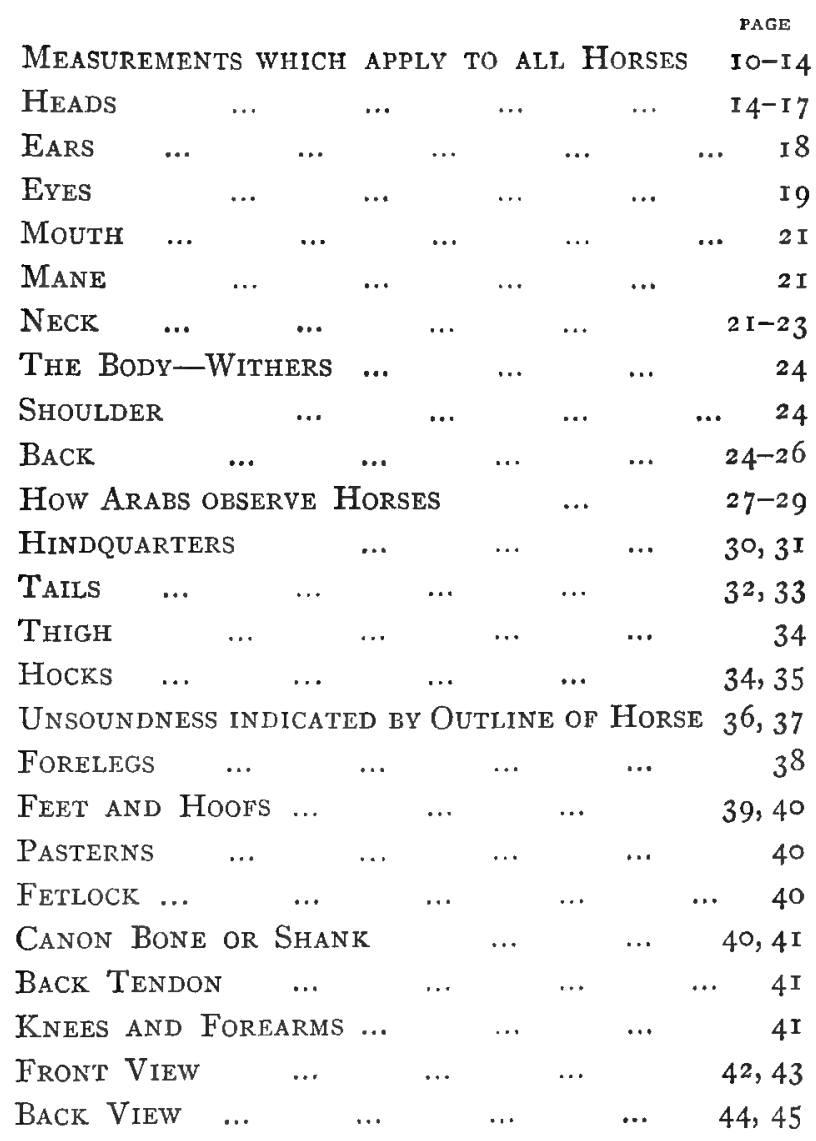

Movements-Seventeenth-Century Opinions

Knowledge obtained by Photography ...

AMBLE

Rotatron in which Horse moves his Legs

Artificial Paces

Peculiarities of Movement

Conventional Horses...

Effect of Motion indicated by Lines

Terms Appreciation, Depreciation

METHODS OF BREAKERS

DoCkING ...

TRIMming

The Rider

JOURNEYS

Tratning Culld's Pony and Teaching ChuLd 74,75 CUT of SADDiES

GirThS $\ldots$

BRIDLES

Driving-COACHMEN

TEAMS OF EIgHT OR MORE

WHIP

HARNESS

Buying at Auction

Tethering
PAGE

$46-48$

48-5 I ... 52

53

53-55

56,57

58,59

60,6 I

... 62

$6_{3}$

... 63

64

$65-7$ I

72,73 ... 74

74,75

75,76

76,77

78

$78-82$

$82-84$

... 84

85

$86-88$

88-90

\section{Digitized by Microsoft@}




\section{LIST OF ILLUSTRATIONS}

FIGS.

I. Skeleton ... Frontispiece PAGE

2, 3. HoRSES DRAWN ACCORDING TO EUCLID I 2, I3 4-8. TyPes of HEads $\ldots \quad$...

9. АвоUt то KICK $\quad \ldots . \quad \ldots \quad$ I8

Io. $\begin{array}{lllllll}\text { G } & \text { AGGED } & \ldots & \ldots & \ldots & \ldots & 20\end{array}$

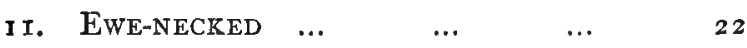

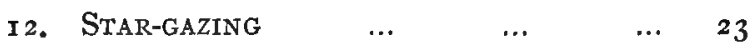

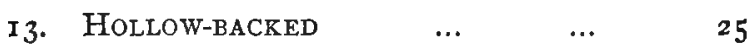

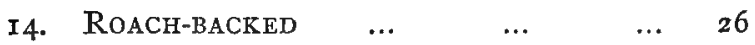

15, I6. Positions in GRazing according to $\begin{array}{llll}\text { The Arabs } & \ldots & \ldots & 28,29\end{array}$

17. ChUCKLEHeAD ... $\quad \ldots \quad \ldots . \quad \ldots \quad 3^{\text {I }}$

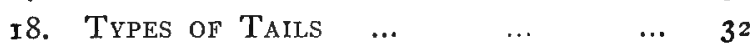

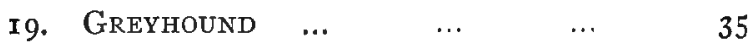

20. Unsoundnesses noticeable in OUt$\begin{array}{lllll}\text { LINE OF HORSE } & \ldots & \ldots & 37\end{array}$

$\begin{array}{lllllll}\text { 21. FEET } & \ldots & \ldots & \ldots & \ldots & 39\end{array}$

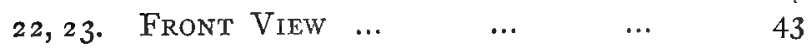

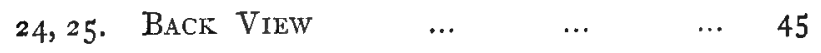

26. The Gallop according to SevenTEENTH-CENTURy IDEAS ... To face $p .48$

27. Jumping Weight Carrier $\ldots$

28. Sketch from Photo of Racehorse ... 50

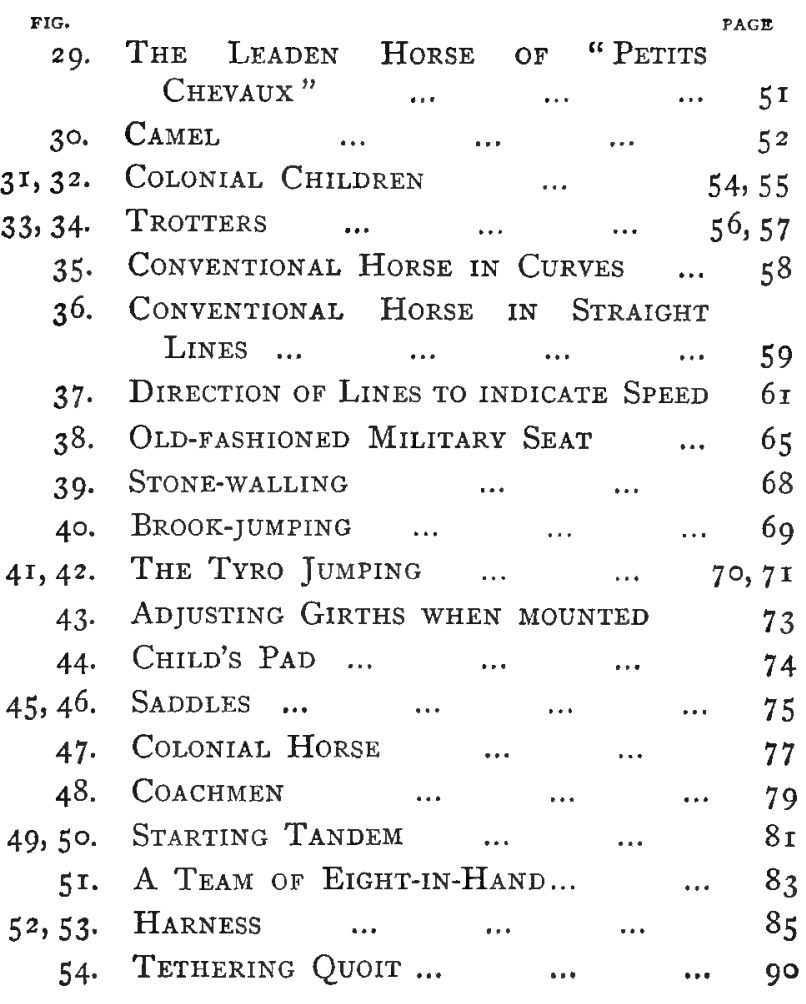

50


Digitized by Microsoft巴 


\section{HINTS ON HORSES}

FIRST and foremost, for a thorough knowledge of the horse, I must emphasize the importance of personal acquaintance with the animal himself, and a careful study of his anatomy (Fig. I). 
By considering the proportions of a horse it is possible to detect his age, to gauge his strength or weakness, and to obtain some insight into his individuality and characteristics. And to understand his proportions it is an assistance to draw them.

Roughly speaking, the body and legs of a horse, when seen standing in profile, may be drawn within the four lines of a square, which should practically include his whole body, with exception of his head, neck, and tail. The height of a horse is equal to the extreme length of his body (Figs. 2 and 3).
Draw a square, $A B C D$, and within it roughly sketch the body and legs so that the feet stand upon the base line, whilst the withers and highest point of the quarters touch the top line; in a well-formed horse the chest and toes of the fore feet should extend to one of the vertical lines, and the back tendon of the hind leg must coincide with the other vertical line.

From the root of the tail draw a perpendicular line upwards to cut $\mathrm{AB}$ at $\mathrm{X}$.

Continue the general line of the forelegs upwards to meet $\mathrm{AB}$ at $\mathrm{Y}$. 
The length of his head, taken from the top of his poll to the tip of his lips, is almost invariably one-third of the distance measured from the poll between the ears to the root of the tail.

It will be found that XY is double the length of the horse's head.
From $\mathrm{Y}$ draw $\mathrm{YZ}=\frac{1}{2} \mathrm{XY}$ at the angle at which you wish the horse to carry his neck. $Z$ will be the poll of the horse.

From $Z$ indicate the horse's head, making its extreme length $=\mathrm{YZ}=\frac{1}{3} \mathrm{ZX}$. 


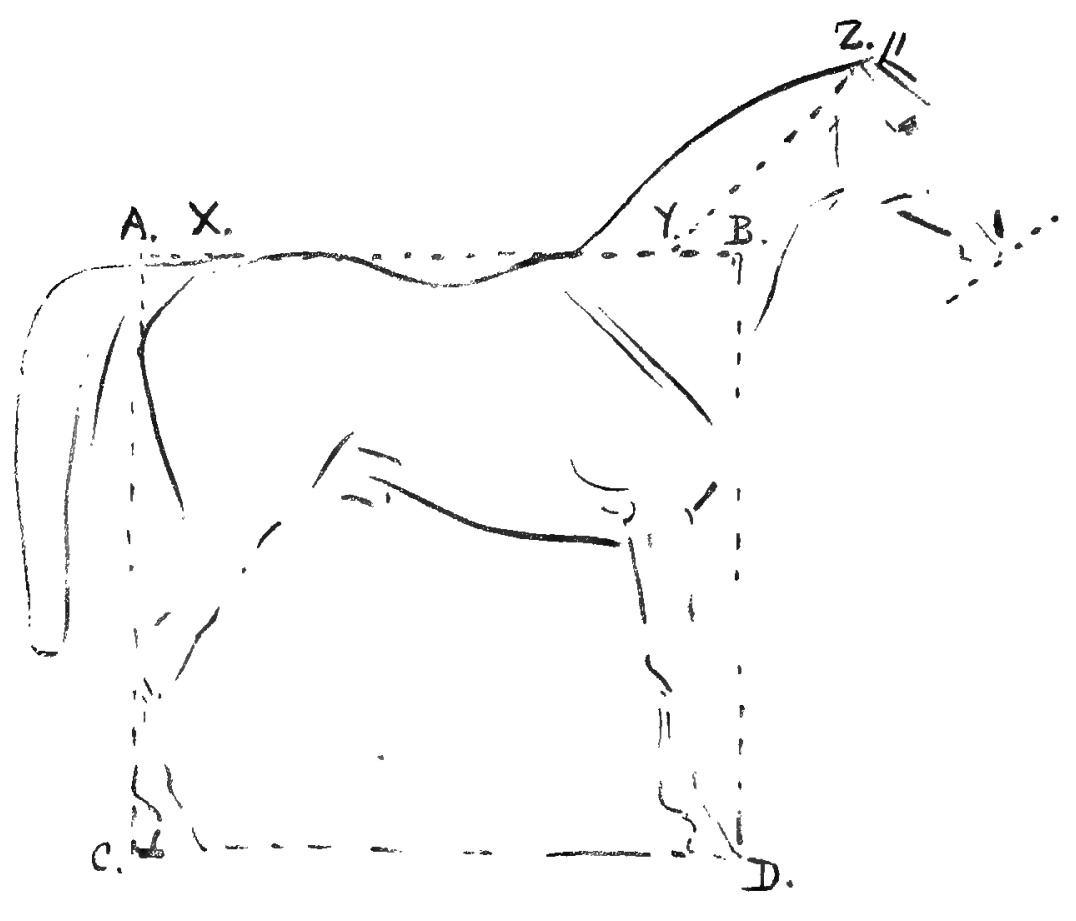

FIG. 2.

Digitized by Microsoft巴 


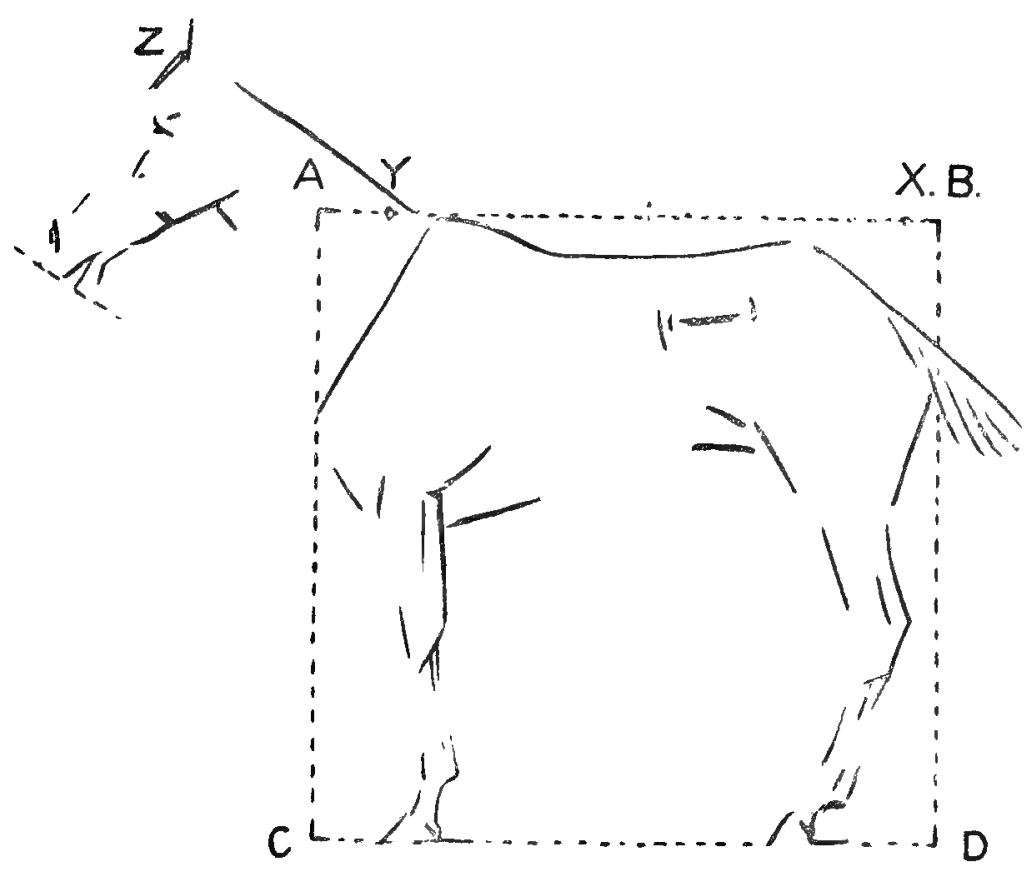

FIG. 3 . 


\section{HINTS ON HORSES}

Having learned the relative proportions of a horse by means of the square, it can be utilized with advantage for drawing purposes.

After drawing the complete outline of the horse, superimpose on it a thin piece of paper, and over the outline which shows through it indicate the salient points and as much more of the horse as is required.

The method is very simple, as may be found by personal experiment.

\section{The Head.}

The heads of horses vary greatly. 
An English thoroughbred has generally a long lean head (Fig. 4).

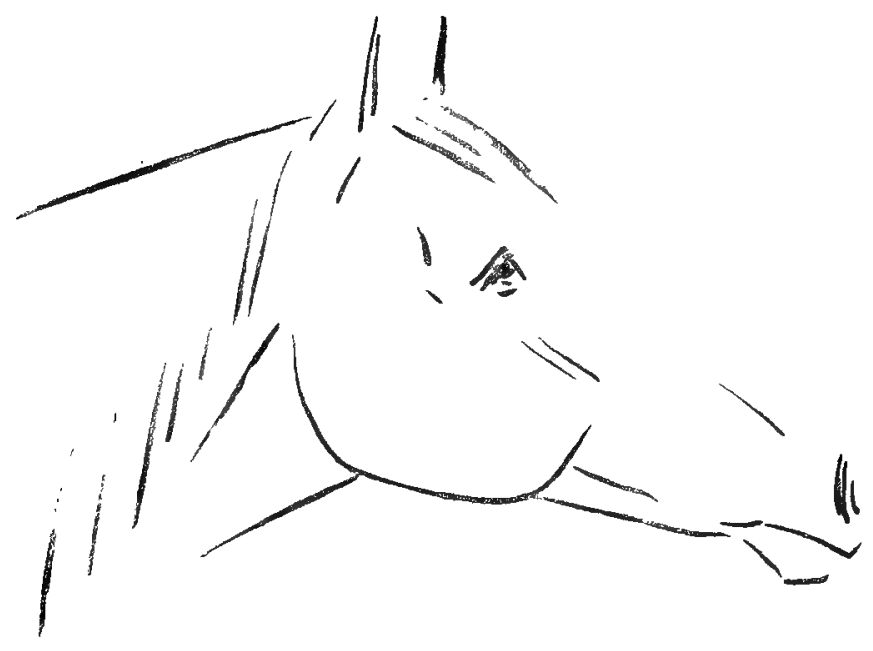

FIG. 4 . 
An Arab (Fig. 5) has a muzzle so fine that he can drink out of a cup. At the same time his head, through the jaw and cheek, is very wide.

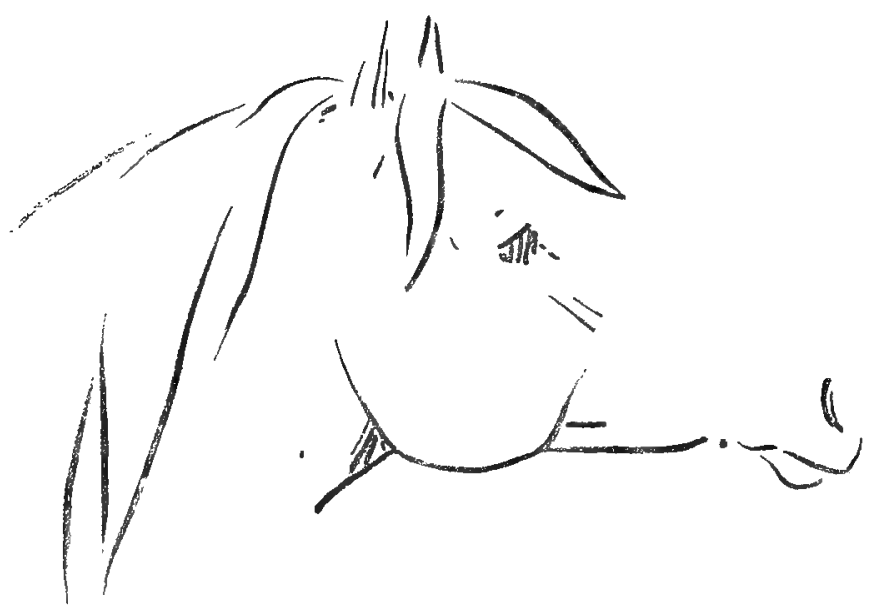

FIG. 5.
An underbred horse's head is vulgarly described as a portmanteau (Fig. 6). 


\section{HINTS ON HORSES}

Nose. -The nose differs in character as much in horses as in human beings: some horses have Roman noses (Fig. 7), others have an indentation on the bridge of the nose (Fig. 8).

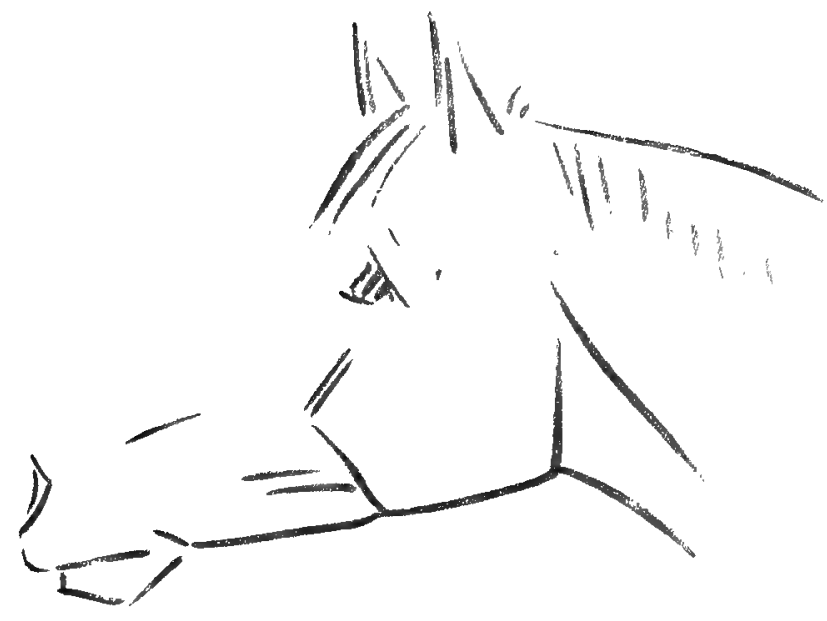

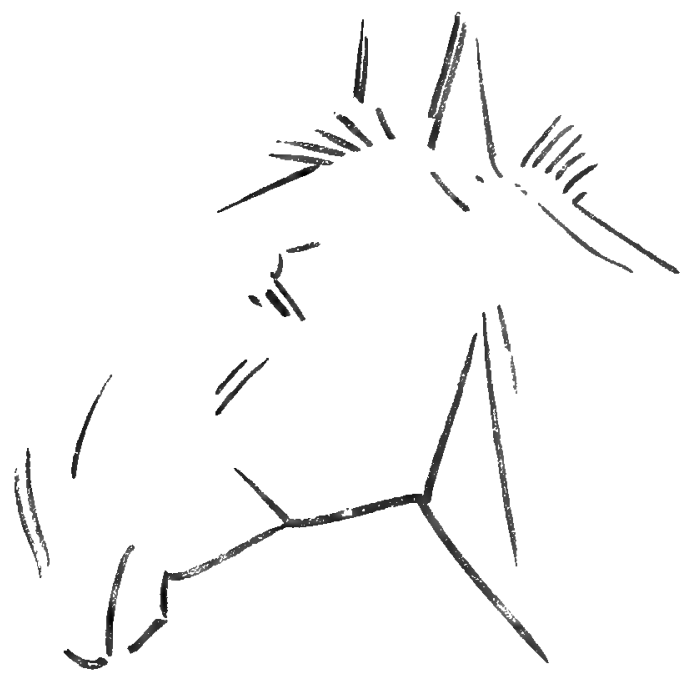

FIG. 7 .

FIG. S, 
Ears.-A horse has much power of expression in his ears, which should not be too small. Lop ears denote stolid good nature. When cocked they denote attention and keenness, when laid back they may mean vice, and foreshadow a bite or a kick (Fig. 9).
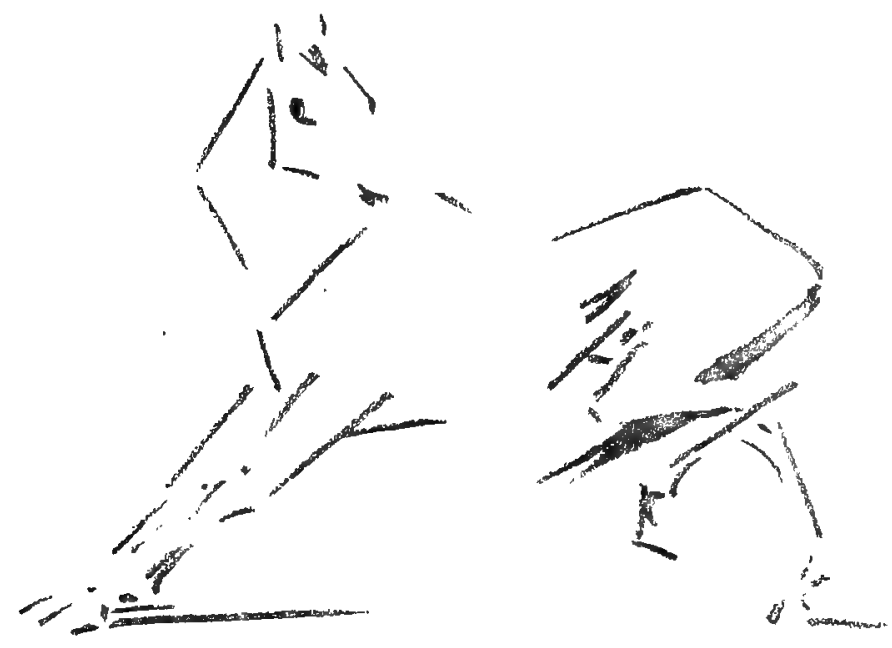

FI'. 9. 


\section{HINTS ON HORSES}

Eyes.-The position of the eye varies a good deal. Roughly speaking, from the poll to the eye is one-third the length of the head. The hollow above the eye deepens with age. A large full eye is expressive of honesty and courage, whereas a small eye may denote cunning. Showing the white of the eye expresses vice.

White Melville wrote that if he had only one portion of a horse to look at before purchase, he would select the eye. 


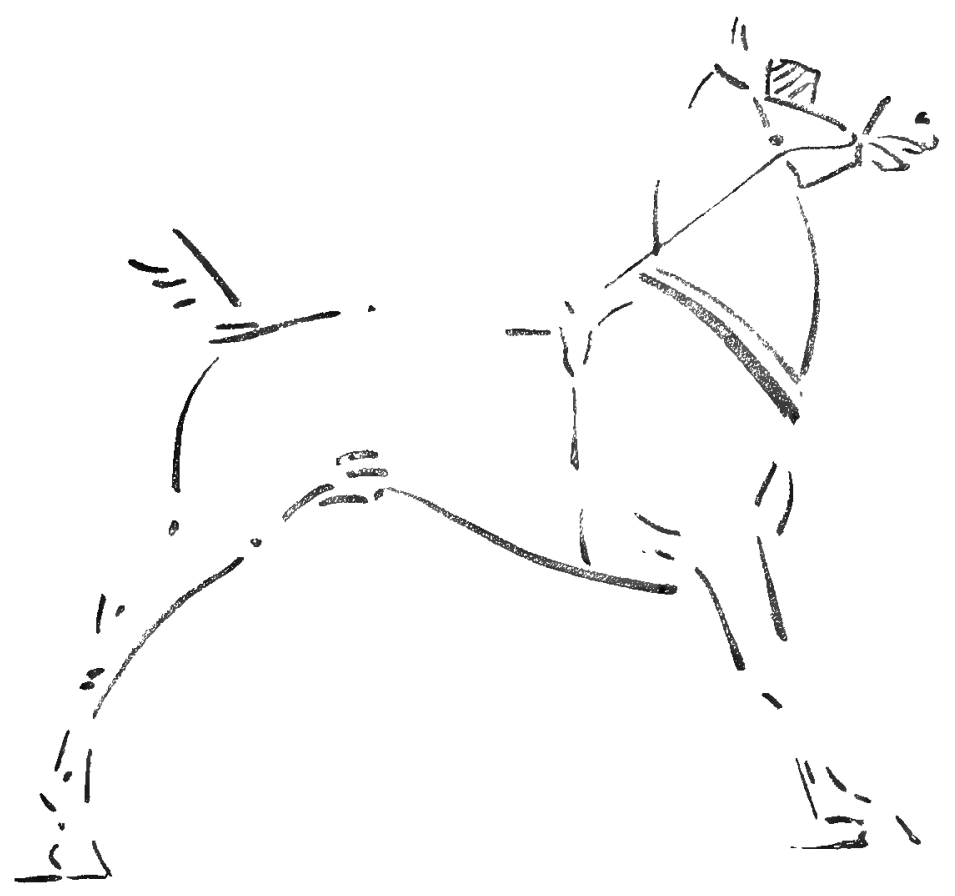

FIG, IO. 


\section{HINTS ON HORSES}

Mouth.-Mouths have many forms. In a young horse the lips are short. A wellbroken horse with a light mouth retains the short lips; whereas pullers, and horses gagged with bit and bearing-rein, acquire long, slit-up mouths. This form of mouth is generally associated with muscular development of the neck (Fig. Io).

Mane.-Well-bred horses have fine, straight manes and tails. Under-bred horses have coarse, bushy, or curly manes and tails.
Neck.-The upper outline of the neck shows condition, and varies from convex to concave. Stallions have convex crest lines. Geldings have straight necks, unless they have been stallions for a few years, in which case they retain the curved crest. A mare's neck is generally straight, but rounds up when at grass. The above remarks refer to a horse carrying its head naturally, without any bridling. 


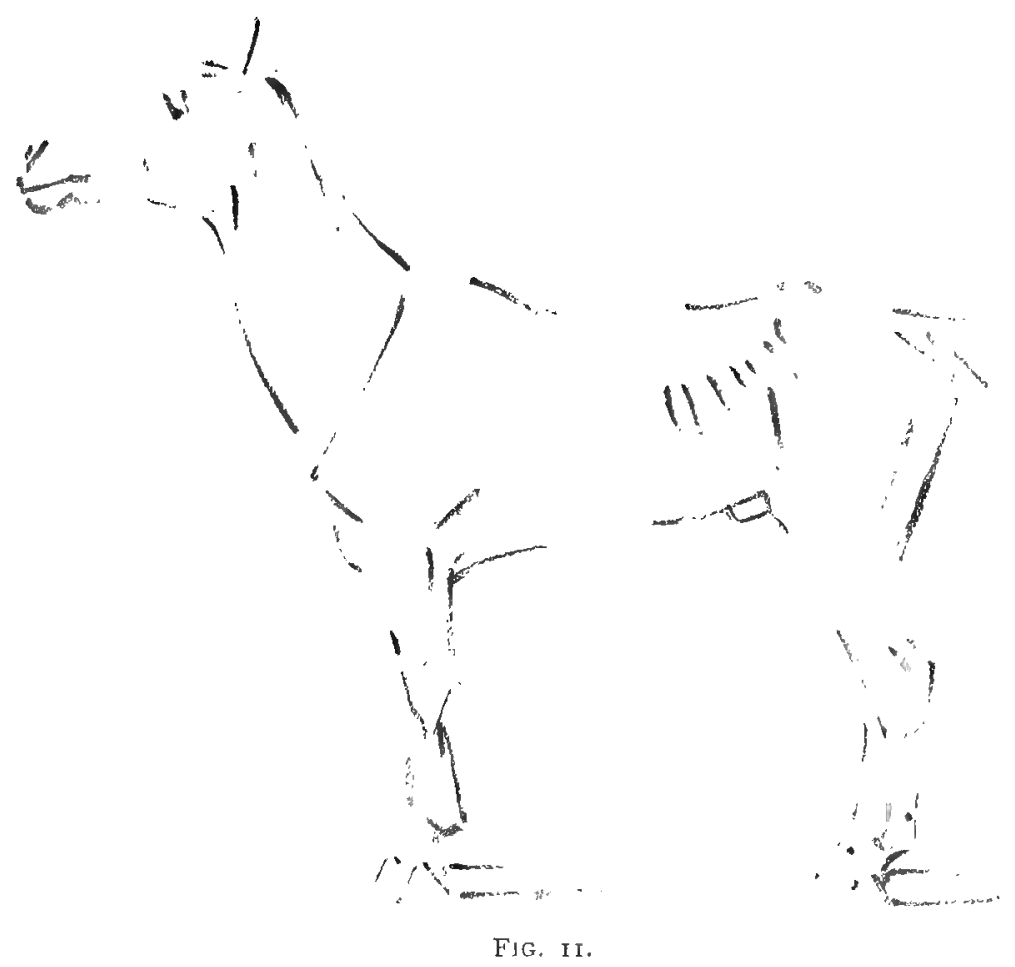

When the outline of the under surface of the neck is convex, the horse is said to be ewe-necked (Fig. Ir). 


\section{HINTS ON HORSES}

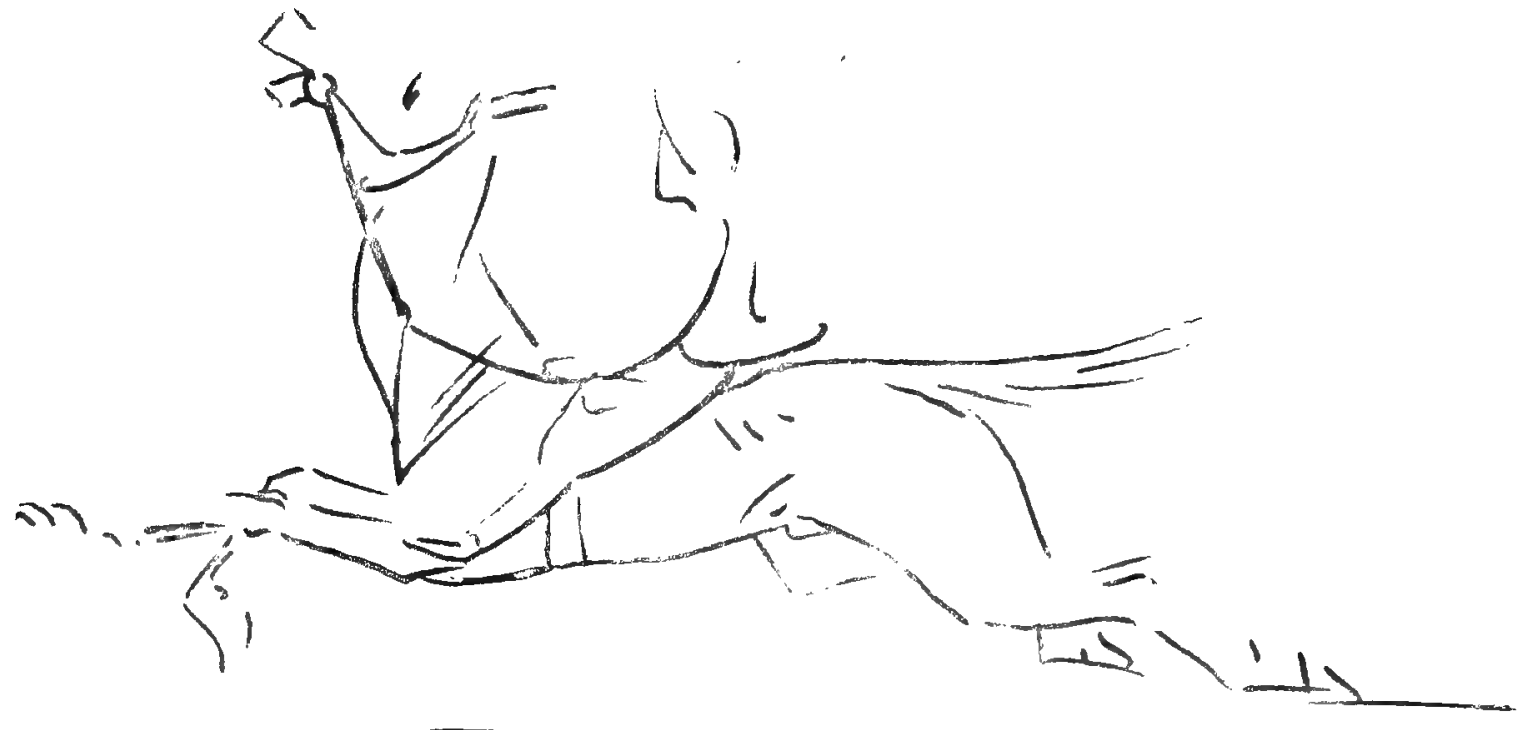

FIG. I2.

Ewe-necked horses are often straight-shouldered; they are often also star-gazers (Fig. I2). 
THE BODY.

Withers.-The withers of a horse must be carefully noted; they vary from almost a razor edge to quite a rounded surface: their position is also of importance; this depends upon the shoulder.

Shoulder.-The most important line whereby the individuality of a horse is depicted is that of the shoulder.

This line may be oblique or upright. If oblique the neck is long, the withers lie back, and the back is short. If upright these proportions are reversed. A head placed on a long neck looks relatively shorter than a head of the same size on a short one.

A lean, clean cut, and angular shoulder is desirable for a riding horse. A rounded, heavy-looking shoulder, on the other hand, is adapted to heavy draught work.

Back.-The length of the back is dependent on the position of wither and size of hindquarters. The shorter the back the stronger. The larger the hindquarters the more powerful. 


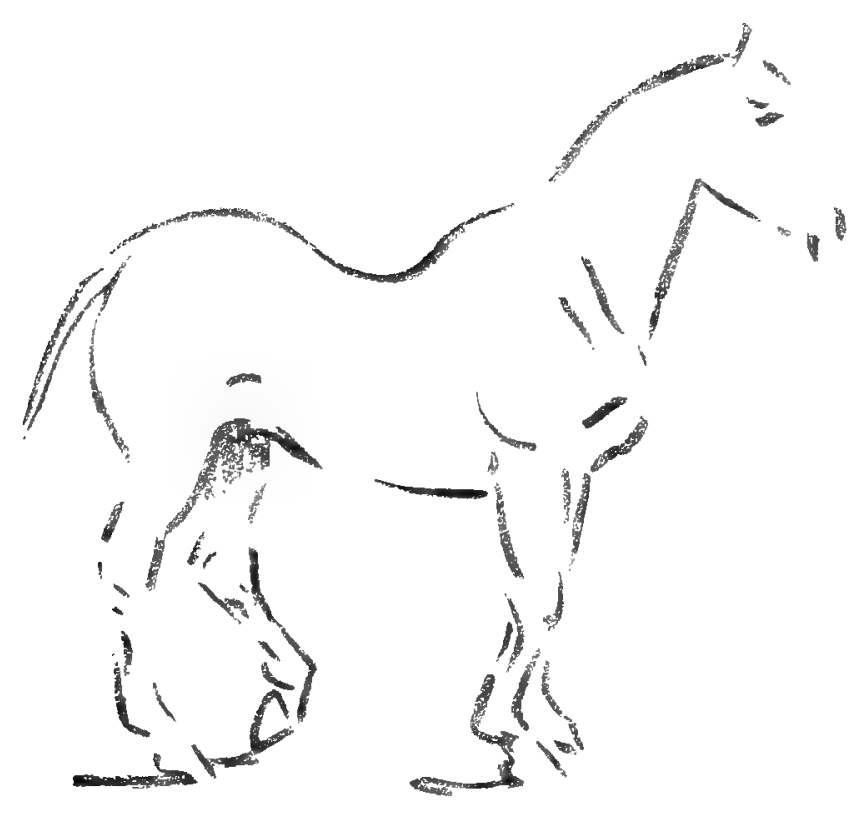

FIG. 13.

In weak or old horses the back is often hollow. Some horses are naturally hollow-backed (Fig. I3). 
In certain cases the back assumes a convex form, known as "roach-backed" (Fig. I4).

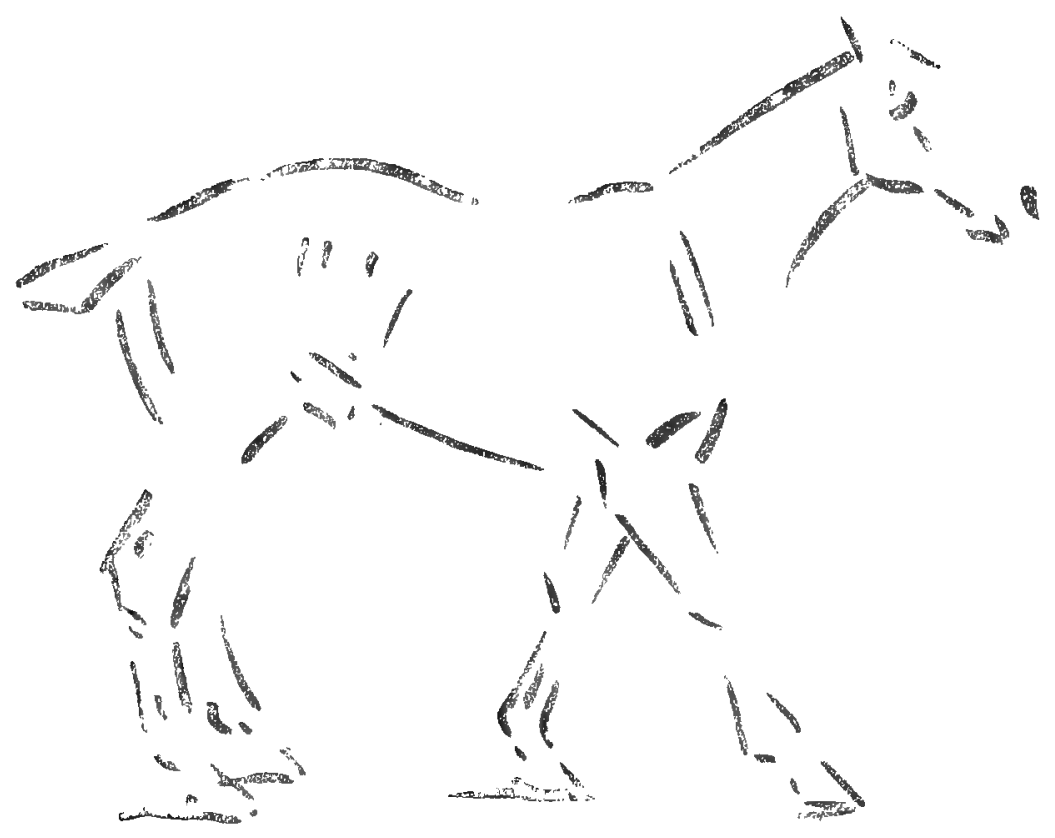

FIG. I4. 
It has been said that Arabs are quick to notice the manner in which a horse stands when grazing on level ground. The pure bred can feed with his fore legs perfectly upright (Fig. I 5); the horse that has some slight flaw in his pedigree shows it by slightly bending one of his fore legs whilst feeding off the ground; and the curly maned, curly tailed underbred has to kneel to get his food (Fig. 16). This observation shows that the Arabs appreciated the beauty of a long rein and a short back. 


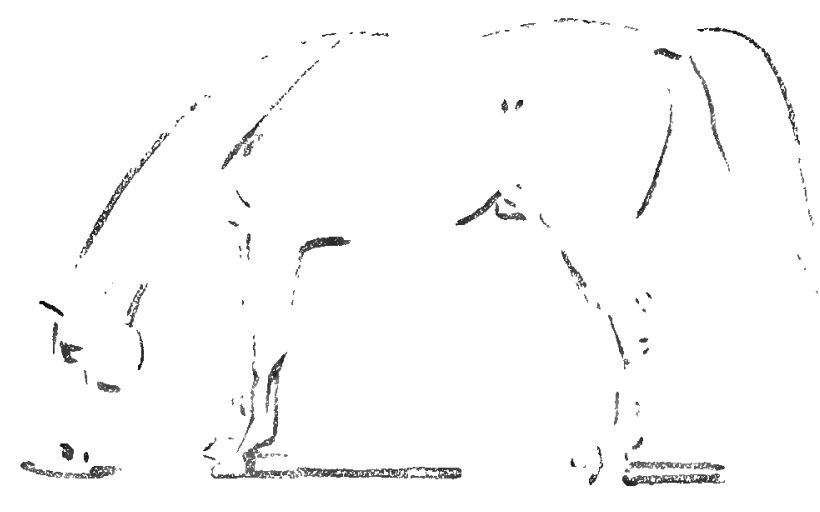

FIG. 15. 


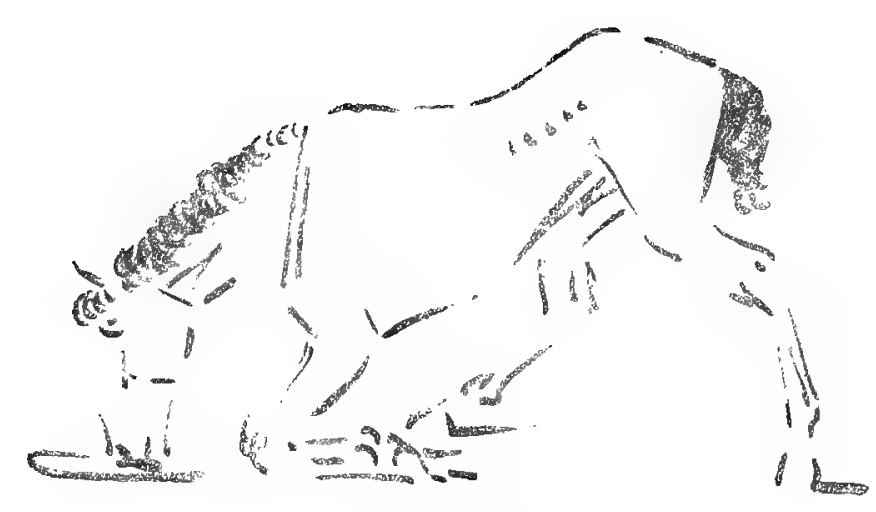

FIG. 16. 
Hindquarters. - A horse's hindquarters may be about the same height as his wither, in which case the hind leg is long and therefore has more driving power.

Long quarters with thighs well let down into the hocks denote speed.

A round full hindquarter may be due to muscle or fat. This is of importance in hunters and racehorses. Hunters are usually grosser than racehorses. Some run fat, others are trained fine. This training is apparent in the haunches and buttocks.

A clear-cut indentation between the haunches and buttocks is called the "poverty line." This line is very noticeable in underfed animals.

Drooping hindquarters are described as "goose-rumped." This formation is often found in Irish horses.

Charles Kingsley showed his appreciation of the points of a horse in the following admirable passage in "Hereward the Wake":-

"The ugliest, as well as the swiftest of mares, she was, say the old chroniclers; and it was not till the stranger had looked twice at her, that he forgot her chuckle-head, greyhound flanks, and drooping hindquarters, and began to see the great length of those same quarters, the thighs let down into the hocks, the compact loin, the extraordinary girth through the saddle, the sloping shoulder, the long arms, the flat knees, the large well-set hoofs, and all the other points which showed her strength and speed, and justified her fame.

" She might carry a big man like you through the mud,' said he, carelessly; 'but as for pace, one cannot expect that with such a chuckle-head. And if one rode her through a town the boys would call after one- 


\section{HINTS ON HORSES}

" "All head and no tail. Why, I can't see her tail for her croup is so ill set on!"'" (Fig. I7).

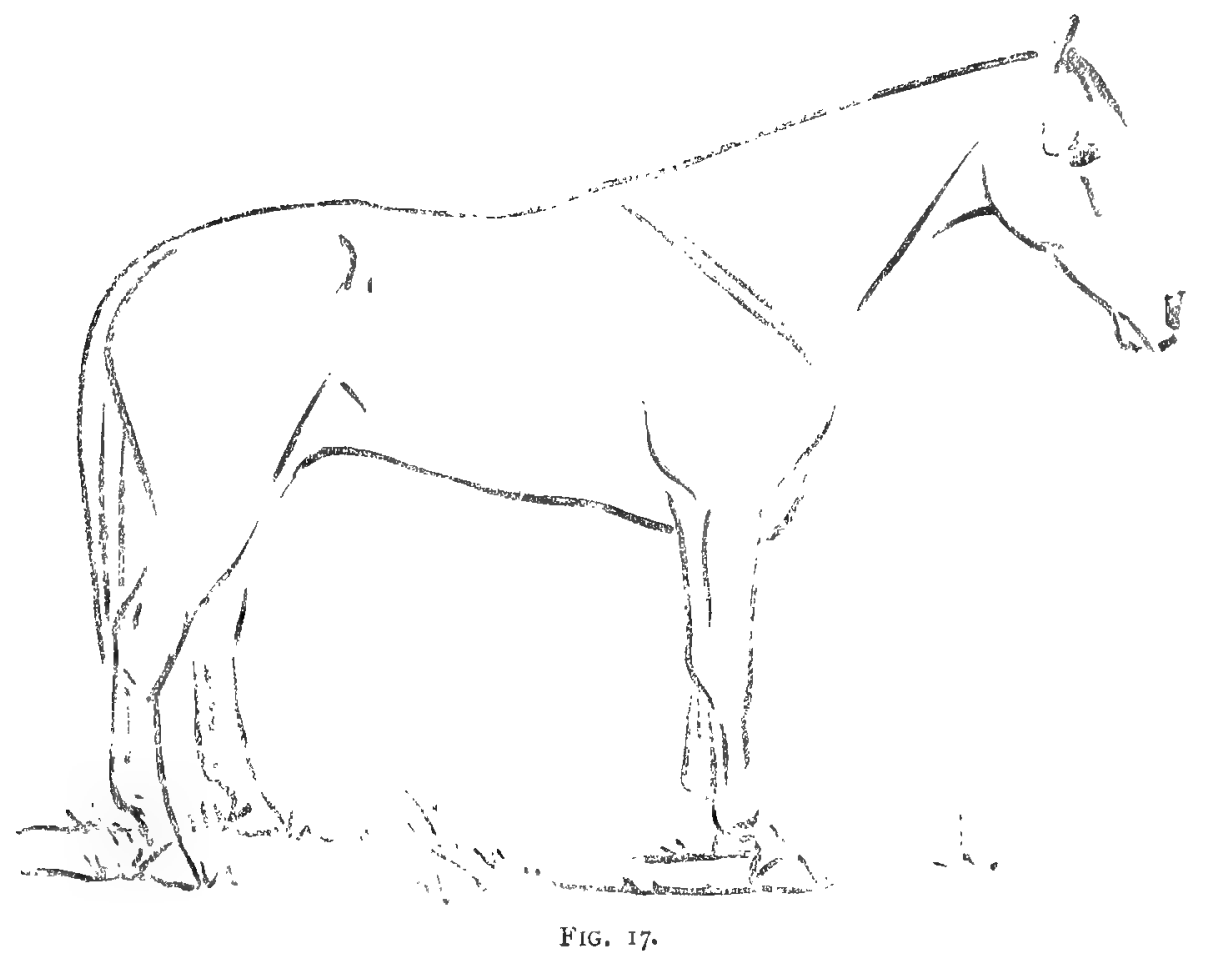

Digitized by Microsoft@ 


\section{HINTS ON HORSES}

Tails (Fig. I8).-When the tail is carried high it denotes life, and is said to be "well put on."

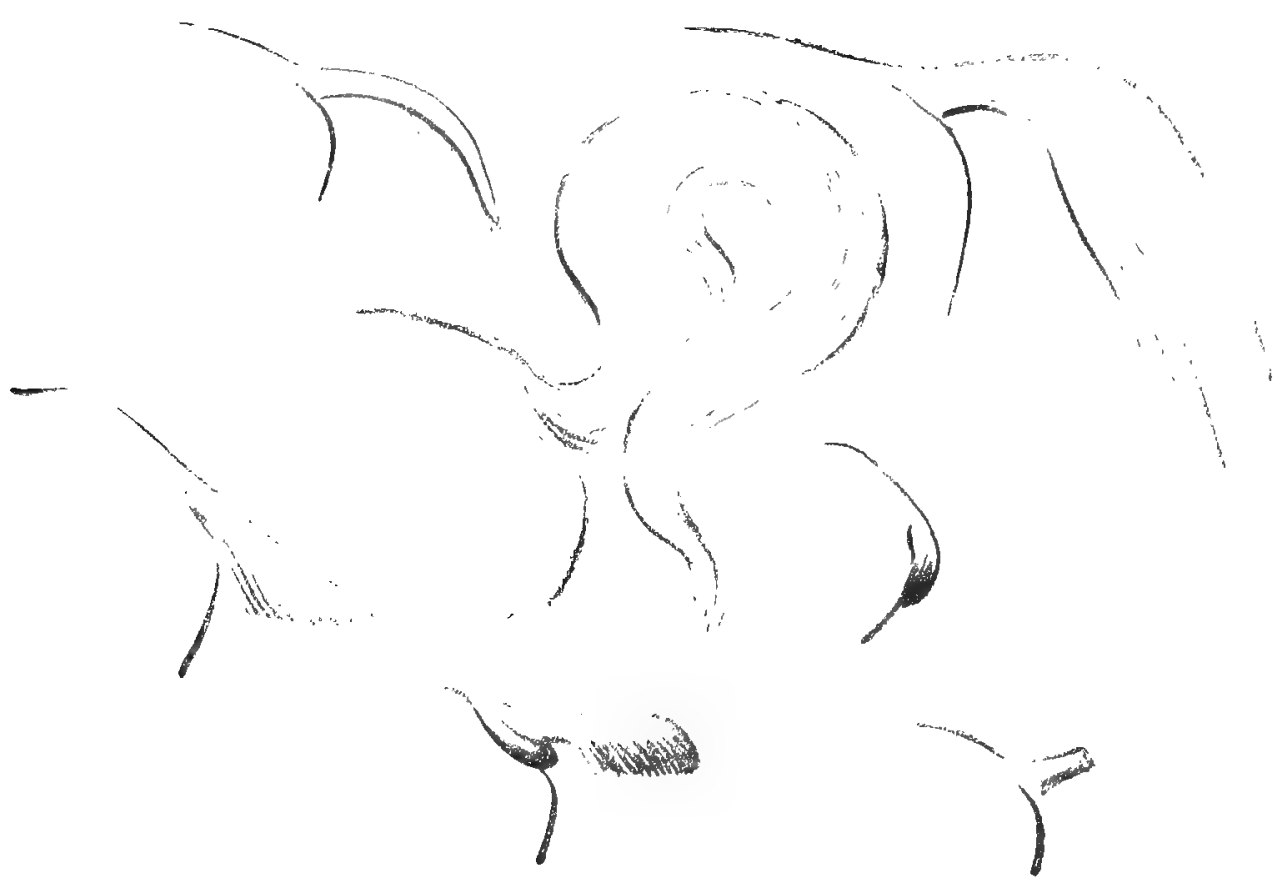

FIG. 18. 
A tail tucked in gives a mean appearance.

Hunters generally have short tails, so as to increase the full appearance of their quarters. Racehorses, on the other hand, have long tails, which suit their long, well-let-down thighs and hocks. A thoroughbred in the hunting-field is often called a "long tail."

Arabs often curl their tails right over their backs.

Some horses have no hair on their tails.
These are known as "rat tails," and there is a saying that there is never a bad horse with a rat tail.

Horses which have their tails docked and trimmed, so as to give a triangular appearance, are known as "fan tail."

Some horses have their tails trimmed so as to terminate in a horizontal line.

A horse with an untrimmed tail, is said to have a "swish tail." 
Thigh--The thigh denotes muscular condition.

Hocks.-A greyhound's hock is ideal for maximum speed. The greater the leverage the greater the speed (Fig. 19).

If the hock is exaggeratedly bent, it is called "sickle hock." 


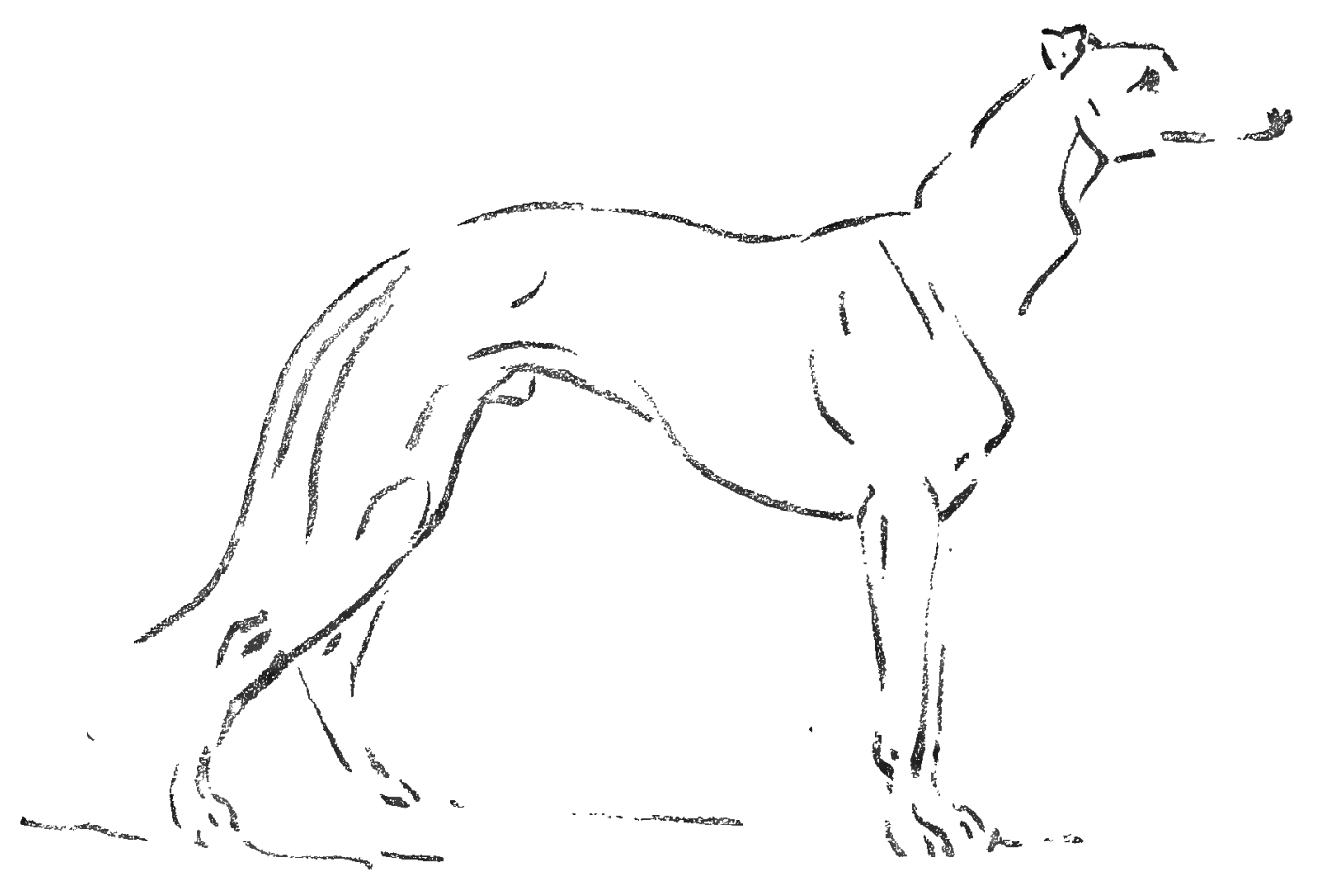

FIG. I9.

Digitized by Microsoft@ 
In a sound horse the rear outline of the hind leg, exactly in profile, from point of hock to fetlock should be a straight line (Fig. 20).

A lump on the point of the hock indicates a habit of kicking in the stable. A joint with such a lump is called a "capped hock" (a).

A similar lump on the elbow is termed "capped elbow" (e). A lump lower down, where the back tendon commences, indicates curb (b), a source of weakness in jumping horses. It is a result sometimes of too much jumping on the part of the horse before he is strong enough.
Many Irish horses are just touched with the firing-iron on the seat of curb.

A bulge in the outline of the back tendon denotes a broken-down leg, known as the "bowed tendon" (c).

The hind fetlocks are slightly higher off the ground than the fore fetlocks.

Around the fetlock, lumps are often only signs of work, and not unsoundness. These are called "wind galls" $(d)$.

If the fetlock itself is swollen, it is often described as "puffy," and this may indicate unsoundness. 


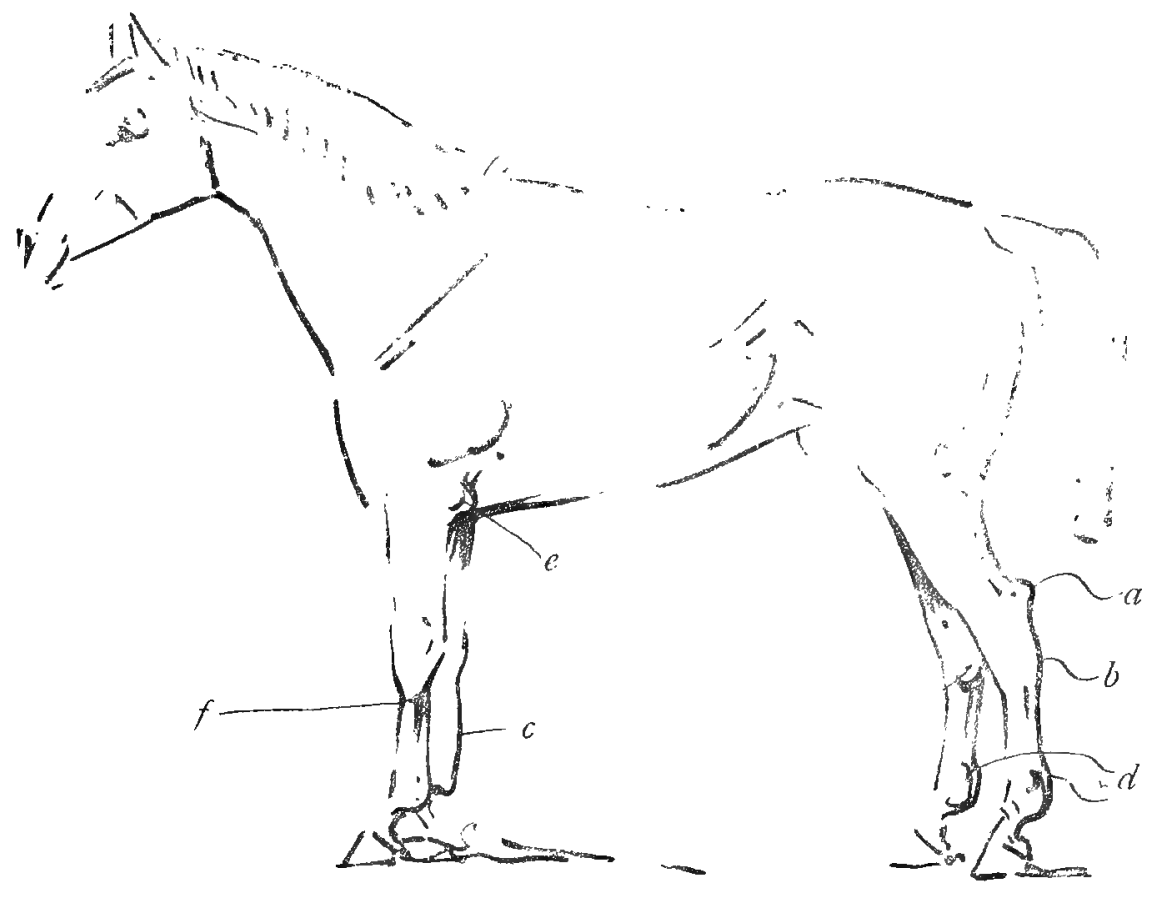

Fla. 2C. 
Fore legs. - The highest point of a horse's body is his wither. In full-grown horses the distance from the withers to the elbow is equal to the distance from the elbow to the centre of the fetlock.

In young horses the elbow is nearer to the withers than to the fetlock.

This fact enables one to depict youthfulness in young stock, and it also enables purchasers of polo ponies, racing galloways, show harness horses, etc., etc., to form a very good idea whether young animals, submitted for their approval, will eventually grow too tall for their particular job.

To make use of the method described above of drawing a horse, it is necessary to place the fetlock.

The position of this joint depends on the angle of the feet, and the springiness or otherwise of the pastern.

Mr. Jorrocks says, "No foot no hoss." 

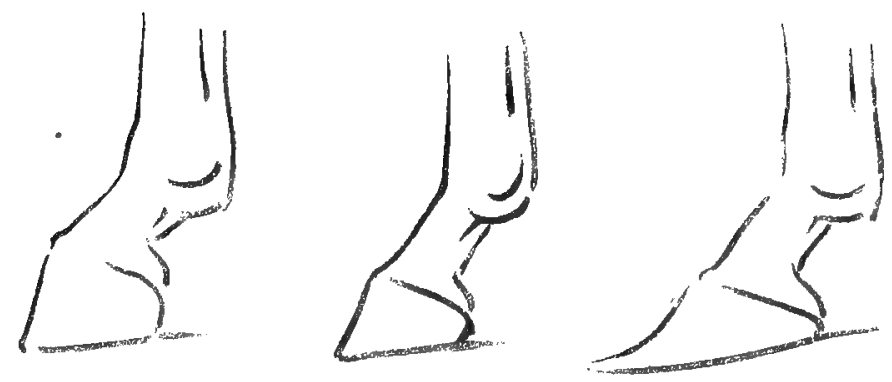

FIG. 21 .

Feet and hoofs.-A good hoof slopes at about an angle of $45^{\circ}$, hind feet are rather more upright than fore feet (Fig. 21).

If the hoof is too upright, its appearance resembles that of a donkey.

If too flat it is indicative of malformation, or the result of neglect or disease.

Underbred carthorses often have this flat foot, so also do some heavy carriage horses.

\section{Digitized by Microsoft@}


A horse should stand firmly on his heels. If the heels, or rather what is known as the "frog," is pared away during the operation of shoeing, a fatal fault of the farrier, the horse will not be able to bring the necessary pressure upon it, consequently the frog will gradually contract and wither, and the horse's shoe will become more and more nearly a closed circle.

If a horse is not shod often enough, the horn or exterior rim of the hoof grows too much, and by degrees perches the foot so high up that the frog is no longer able to touch the ground, and a similar result, to that just described, ensues.

If a horse has never to go on macadamized or artificially hardened roads, it is often best not to shoe the animal at all; then the frog is always on the ground, and the horn of the foot wears away naturally. Heavy horses have big feet, thoroughbreds small feet. The feet of underbred horses are larger than those of thoroughbreds.

A big foot in a hunter is said to be of value in heavy countries; but, on the other hand, there is the saying that "blood will tell,"
Pasterns. - The pastern may be oblique or upright.

Wellbred horses have oblique pasterns, which render their action springy.

Underbred horses have straight pasterns, and their action is rough and inclined to jar. An oblique pastern carried to extremes denotes weakness, as in young underfed stock.

Fetlocks.-The fore fetlocks, as in the case of the hind legs (see above), show if the horse has done much work, when they are large or "puffy;" this puffiness does not necessarily affect the soundness of the action of the horse. The upper portion is liable to little swellings known as wind galls.

A horse which has been standing in the stable too long often comes out with big fetlocks, but after a little exercise the joint assumes its normal dimensions.

A hunter the morning after a long day is often rather swollen about the fetlocks; in its case also exercise reduces the swellings.

Canon bone or shank.-A horse's canon bone (the bone below the knee) should be like a barod, narrow when seen from the front, wide 
when seen in profile. It is a quality for a horse to be what is called "big in the bone," in other words big below the knee, but this bigness should be as above described.

In 1658 the Duke of Newcastle wrote, "I have experienced this difference between the bone of the leg of a Barbary horse and one from Flanders, viz. that the cavity of the bone in one shall hardly admit of a straw, whilst you may thrust your finger into that of the other."

Thoroughbreds have fine-looking legs; their bone is often compared to ivory. If a horse's canon bone is small, it is often described as being "tied in below the knee" (Fig. 20,f). This is a source of weakness.

Back tendons.-Behind the canon bone is the back tendon, which forms part of the posterior outline of the leg when seen in profile. About halfway down the shank the suspensory ligament shows itself, like a taut cord supporting the fetlock. In perfectly sound fresh horses these tendons and ligaments show up very sharply, and catch the eye. In sunshine the shadows they cast make regular accents.
Any bulges or swellings on these denote unsoundness.

Knees and forearms. - Having placed the fetlock and the withers, we can now place the elbow, if for a full-grown horse, halfway between the two. From the elbow to the knee is the forearm. This shows muscular development, and its condition indicates the condition of the horse. To place the knee we must take into consideration the character of the horse. The lower the knee is placed the greater the capacity for speed. As an example study the greyhound.

The lower the knee, the longer the forearm, and the shorter the shank. A term of approval is "short canons," or short below the knee.

The knee should be large and flat. The elbow sometimes has a lump similar to a "capped hock." This is termed "capped elbow" (Fig. 20, e). It is generally due to a horse, when lying down, resting his elbow on the heel of his shoe, thus showing that the shoe wants shortening. If this shortening is overdone the end of the shoe, which must always take the horse's weight, will press 
into the foot when he is standing, and will cause a corn to develop.

Unshod animals when lying out in very wet weather sometimes perch themselves up on their feet so as to keep their chests away from the damp ground, and in consequence suffer from capped elbow.

\section{Front View.}

Regarding the horse from the front, width means strength (Fig. 22); narrowness, speed (Fig. 23). A thoroughbred weed is sometimes described as having both fore legs growing out of the same hole. Such a one may be very speedy for a short distance, but is not a stayer. A horse to stay must have room for his lungs. The room obtained perpendicularly conduces to speed, and horizontally to strength. An example of this theory may be taken from the comparison of the greyhound with the bulldog.

Horses' legs should be perpendicular. Knock-kneed horses are called "calf kneed."

Many horses turn their toes out more or less. This is a source of weakness, because the foot in the air, moving forward, is apt to hit the fetlock of the other foot when on the ground. To remedy this the inside of the shoe should be made thicker than the outside, causing the horse to stand on the outside edge of his foot, thereby forcing the fetlock more nearly into its proper position.

Some horses turn their toes inf, a strong but ugly formation.

Care should be taken to draw the pasterns clean. Any swellings of the outline would indicate ossifications known as "ring bone," etc. In the canon bone, also, lumps should be avoided, unless you wish to indicate that the horse has splints. In which case be careful also where you place them. If high up near the knee-joint either on the outside or the inside outline of the leg the splint would probably cause lameness, by interfering with the attachments or pressing on the ligaments or tendons. Whereas halfway down the canon bone the horse can have a very big splint quite clear of the tendons, etc., and one which once formed and hardened will in no way affect his soundness. 


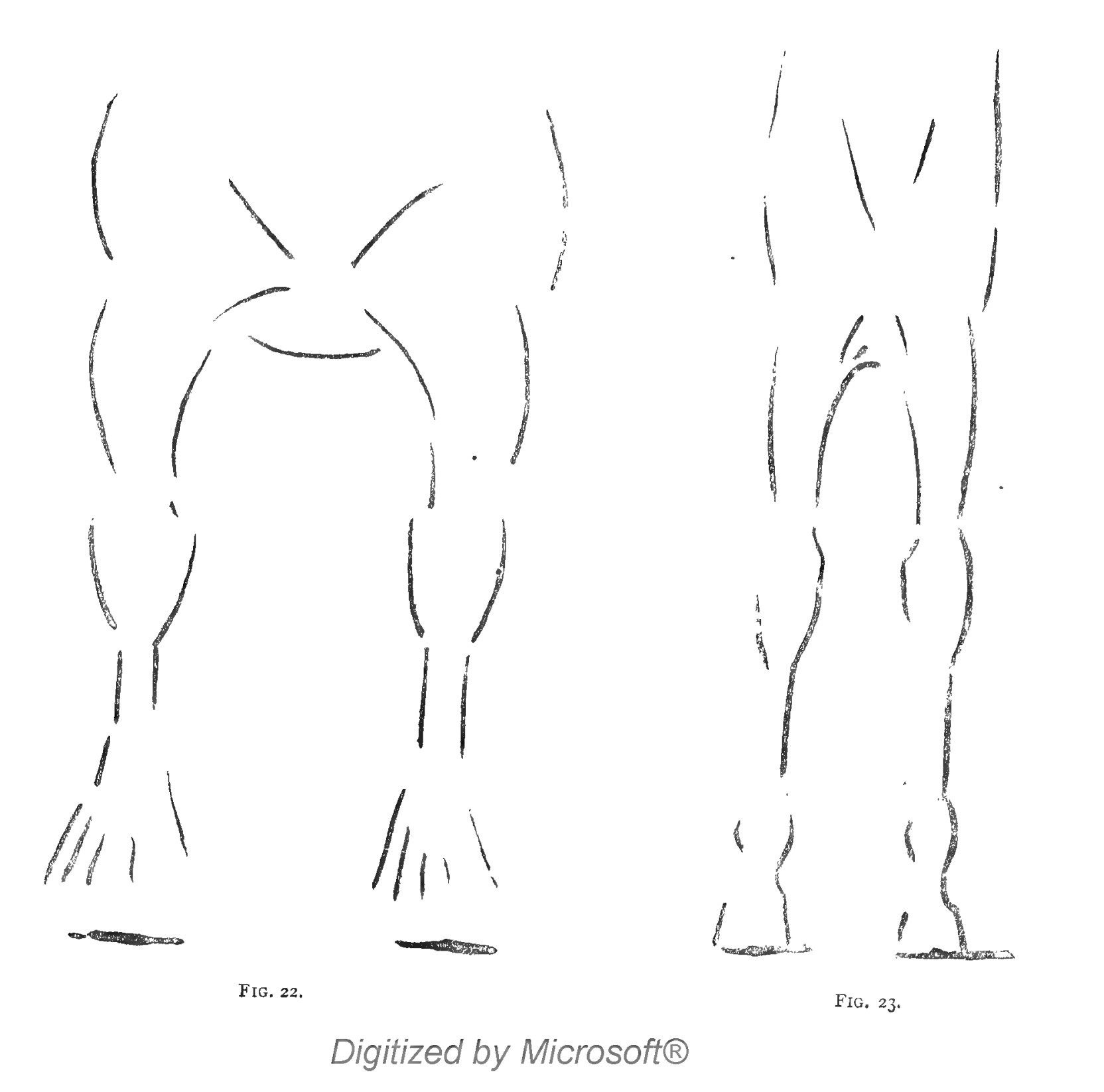




\section{BACK VIEW.}

Seen from behind, some horses are very wide between the hips. The hips are "ragged" looking (Fig. 24). These horses generally stand with their feet close together.

They are often slack in the loins. Some horses are wider through the barrel than between the hips. They generally stand with their feet wide apart, and may generally be counted upon for "good doers" (Fig. 25).

The remarks on ring bones, splints, etc., apply equally to the hind leg, but splints are much more common on the fore leg than on the hind. In drawing the outlines of the hocks, care must be taken to make them a pair. If there are indications of lumps or bumps on one hock which are not equally apparent on the other hock, then the chances are that the horse is "spavined." If, however, both hocks when looked at from a similar angle are identical in outline, it is possible that the animal if not quite clean may be only what is termed "coarse hocked." If the hocks are close together and the feet separated farapart, the formation is described as "cow-hocked." 


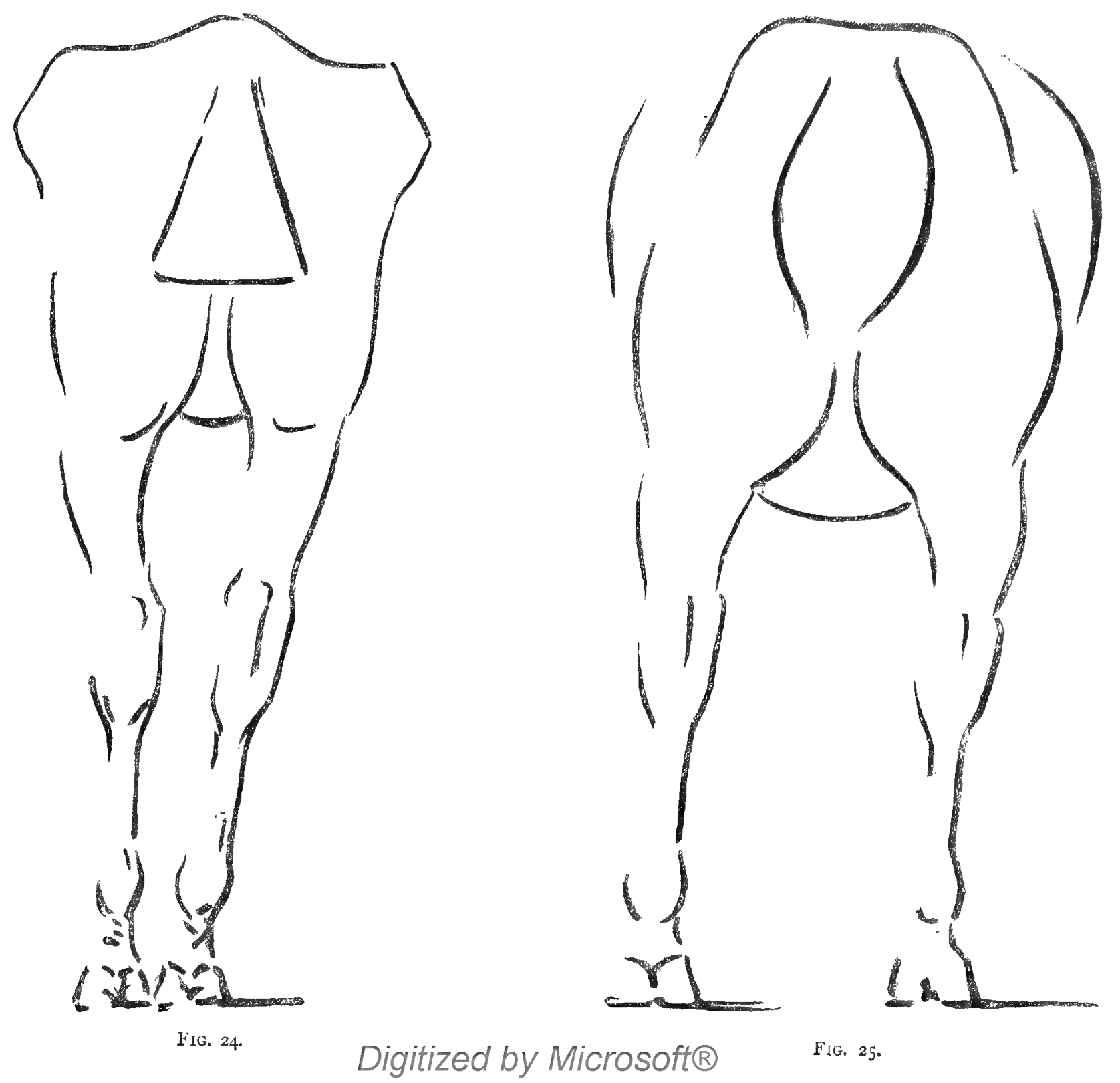




\section{Movements.}

The movements of a horse cannot be better described than by the words of the Marquis of Newcastle, who, in his book on "Horsemanship," * written in 1658 , says-

"I. A horse, in walking, has two of his feet in the air, and two upon the ground, which move otherways at the same time, one fore and one hind foot, which is the movement of a gentle trot.

"2. The trot.-The action of his legs in this movement is two feet in the air, and two upon the ground, which he moves crossways at the same time; one fore and hind foot across, which is the movement of the walk: for the movement of a horse's legs is the same in walking as in trotting, where he moves them crossways, two in the air across, and two upon the ground at the same time; so that those which were across in the air at one time, are afterwards in the same situation upon the ground, and so vice versâ. This is the real movement of a horse's legs in trotting.

\footnotetext{
* Chap. II. vol. i. p. 30 .
}

"3. The amble.-A horse in this action moves both legs on the same side; for example, he moves his two off-legs both before and behind at the same time, while those of the near side are at a stand; and when those two which were in motion before touch the ground, he moves the other side, viz. the fore and hind leg on the near side, and the off legs are then at rest. Hence a pacing horse moves both legs on one side, and changes the side at each motion, having both legs on the same side in the air, and those of the other side upon the ground at the same time, which motion is the perfect amble.

"4. The gallop.-Galloping $\uparrow$ is a different movement; for in this pace a horse can lead with which leg the rider pleases, but the leg on the same side must follow it; I mean when he gallops directly forward, and then this is a true gallop. But that the leading of the fore leg may be rightly understood, which ought to be followed by the hind leg at the same side, the leg moves in the following

$\dagger$ It is obvious that the Duke of Newcastle uses the words "gallop" and "run" in a sense different from that of modern use, and that his "gallop" corresponds to our "canter," and "run " to our "gallop."

\section{Digitized by Microsoft@}


manner: for example, if the fore off leg leads, it consequently follows by such leading, that the same fore leg ought to be before the other fore leg, and the hind leg on the same side ought to follow, which hind leg ought to be before the other hind leg, which is the right gallop.

"But in order to understand it the better, the motion in galloping is in this manner: the horse raises his two fore legs at the same time in the action I have described, which is one leg before the other, they are immediately followed by those behind; so that, as I have said before, they are all in the air at the same time: for his hind legs begin to move when the fore legs begin to fall, by which the whole horse is entirely in the air. How would it otherwise be possible, that a horse in running should leap twice his length, if the motion of the gallop was not a leap forwards? This description is very just both with respect to the motion and posture of a horse's legs in galloping, which, though it be true, is not easily perceived in a gentle gallop, but very visible in a swift one, where the motion is violent: I say, his four legs may then plainly appear to be in the air at the same time, running being no more than a quick gallop, the motion and posture of a horse's legs being entirely the same. It is, however, necessary to observe, that a horse in a circular gallop ought to lead with his two legs within the volte, viz. his fore leg and hind leg within the circle.

"5. Running.-The motion of a horse and the action of his legs are the same in running as in galloping, the different velocity of the motion only excepted; so that running may be properly called a swift gallop, and a gallop slow running. This is the true movement in running. The trot is the foundation of a gallop; and the reason is, because the trot being cross-ways, and a gallop both legs on the same side, if you put a horse upon a trot beyond the speed of that pace, he is obliged, when his off fore leg is lifted up, to set down his near hind leg so quickly, that it makes the hind leg follow the fore leg of the same side, which is a real gallop; and for this reason a trot is the foundation of a gallop."

\section{Digitized by Microsoft@}




\section{HINTS ON HORSES}

The Marquis of Newcastle says that all four legs of a galloping horse are off the ground at the same time.

Instantaneous photography, on the other hand, leads one to believe that one leg of a horse is always on the ground except when jumping (Fig. 27). 


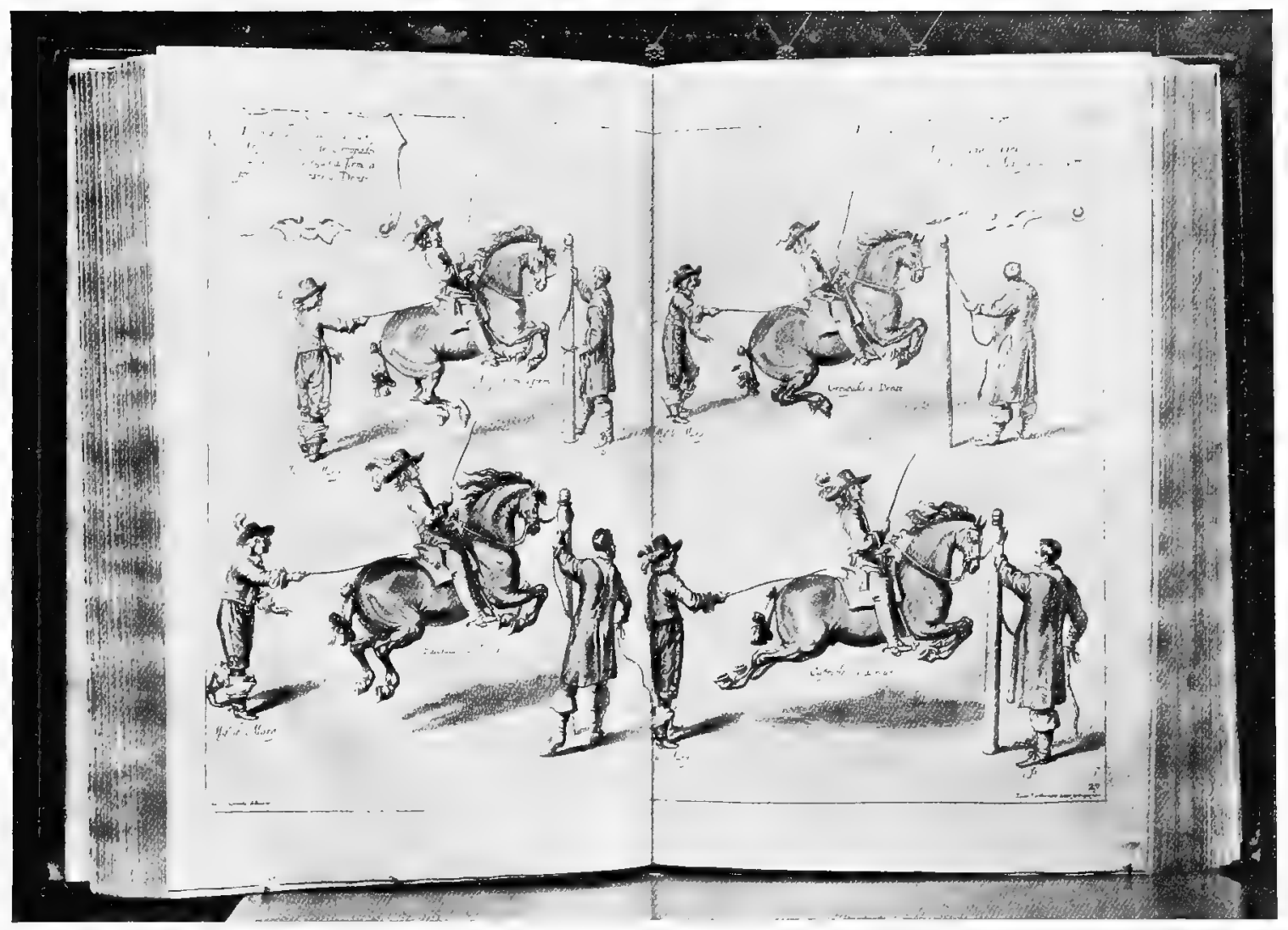

Fig. 26.-Copy of Illustration taren from the Marquis of Newcastle's Book on "Horsemanship," PUBLISHED 1658.

[To fact $p \cdot 48$

Digitized by Microsoft ${ }^{\circledR}$ 
Digitized by Microsoft巴 


\section{HINTS ON HORSES}

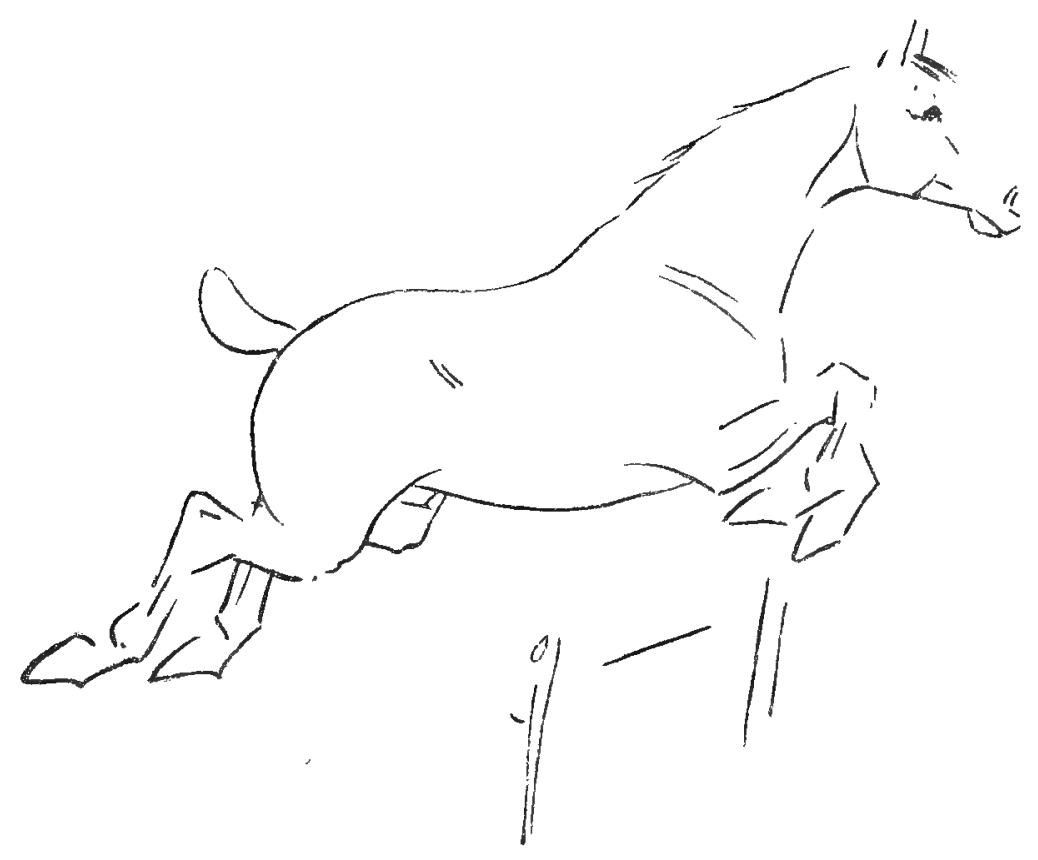

FIG. 27.

Digitized by Microsoft $\circledast$ 
It is very doubtful whether instantaneous photography conveys the impression of motion. It adds greatly to our knowledge, and in the case of jumping horses gives an excellent idea; but, in my opinion, the feeling of speed in a galloping horse is scarcely conveyed by photography (Fig. 28).

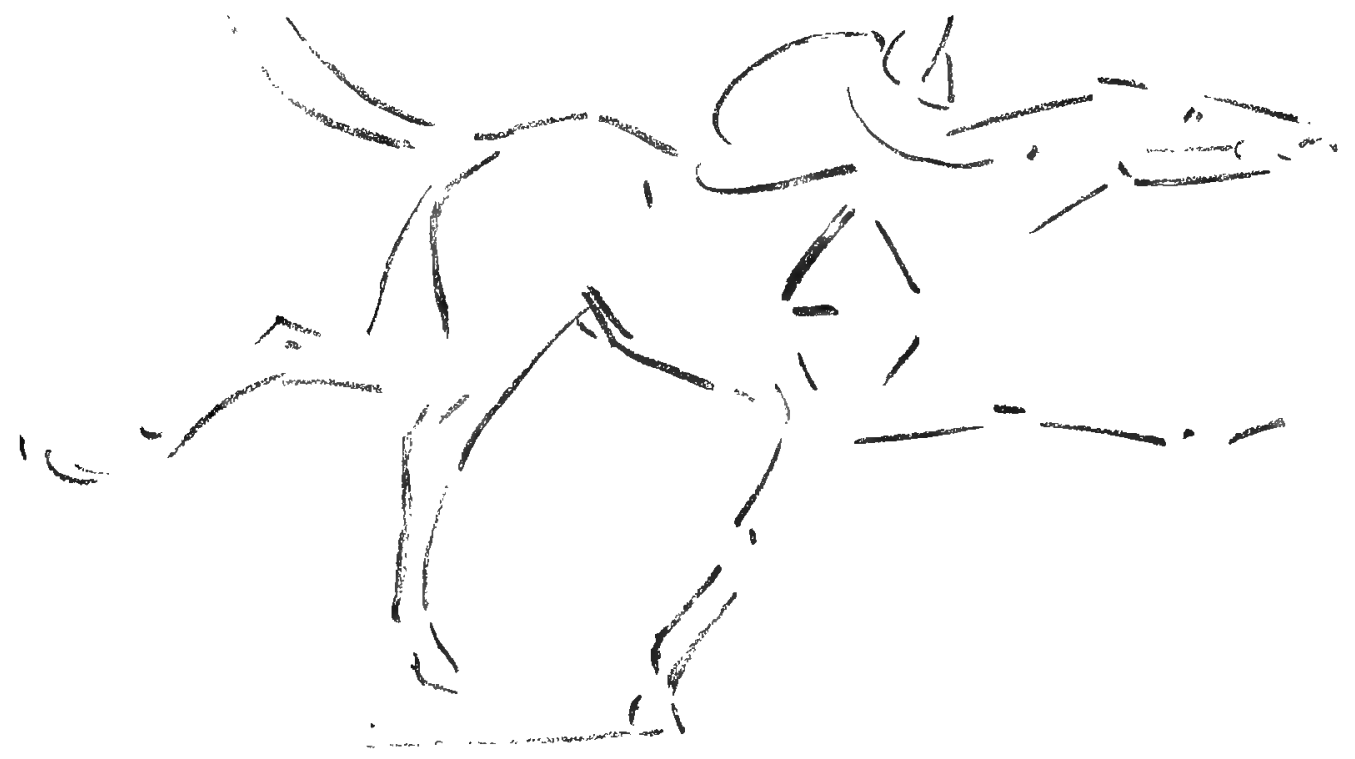

FIG. 28. 


\section{HINTS ON HORSES}

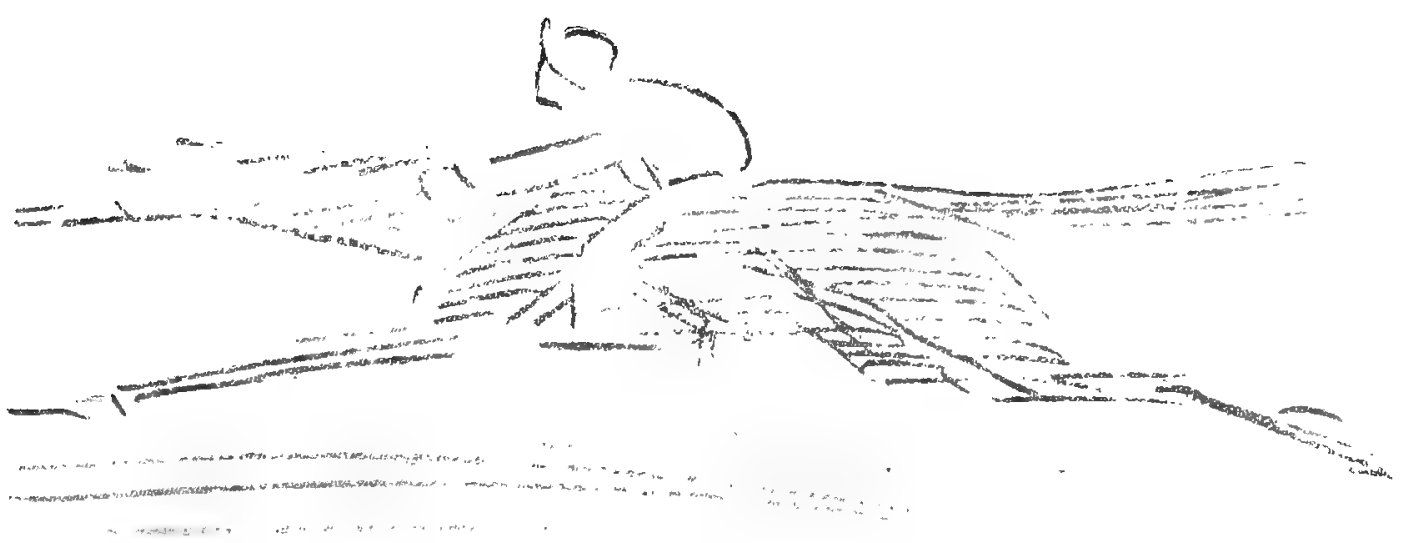

FIG. 29.

In all probability the conventional position (Fig. 29) of the leaden horses in the race game conveys to the mind the better impression of speed. At a walk, trot, canter, or gallop horses move their feet in the following order, viz. near fore, near hind, off fore, off hind. 


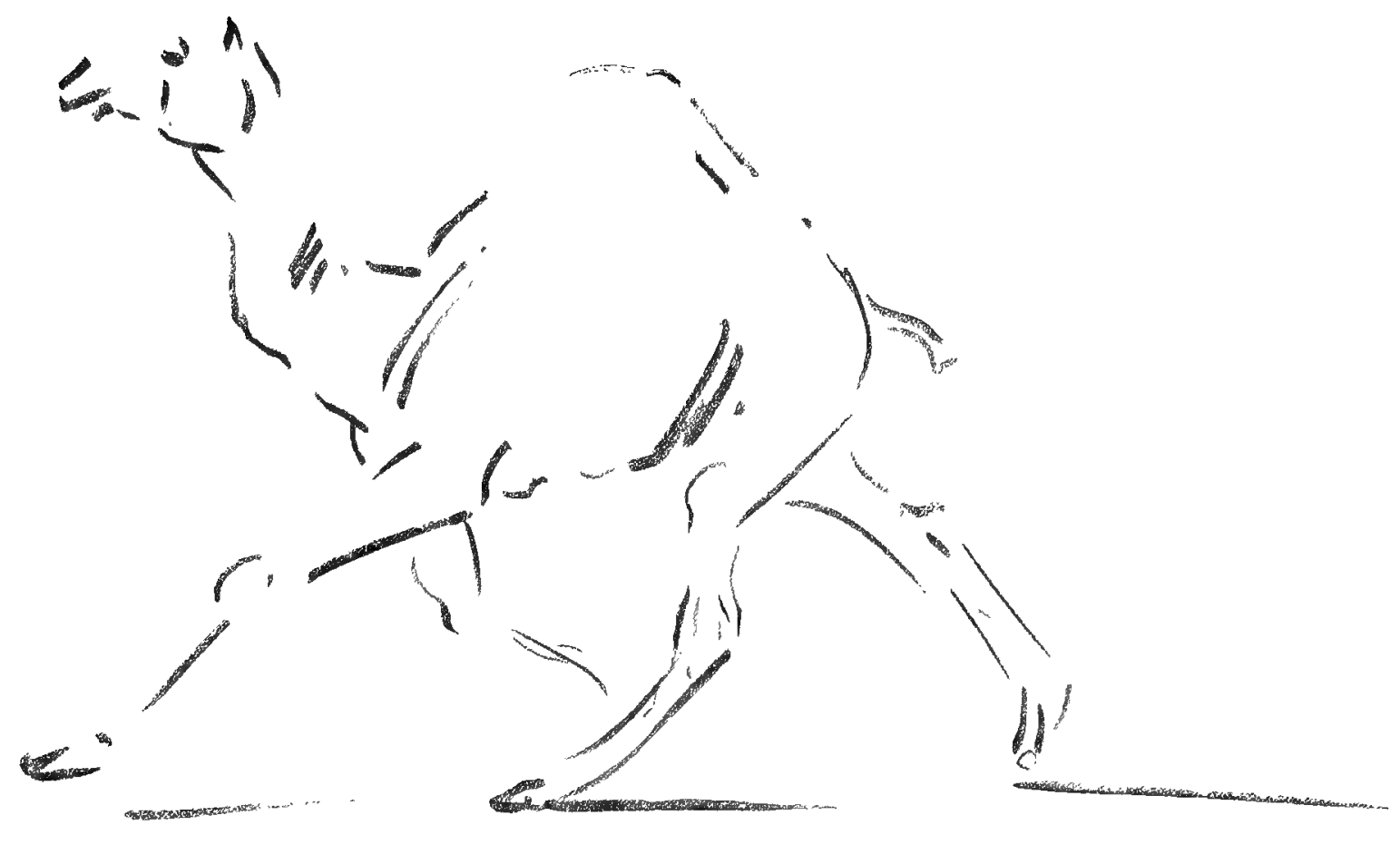

FIG. 30.

At an amble or triple they move like a camel, viz. near fore, off hind, off fore, near hind (Fig. 30). 
A horse places his hind feet almost exactly on to the footprints of his fore feet. If going lazily, the hind feet do not reach to the fore-foot prints (Fig. 3I): if over-exerting himself, he generally goes wide behind, and places his hind feet beyond and outside the fore-foot prints. If walking, a horse has not got up much impetus, and each pace is only about half his length. As he increases his speed he gets up momentum and his paces increase until he is no longer able to progress at a walk, and breaks into a trot. Similarly from a trot he gradually extends to a gallop, until at his utmost speed he is extended to his full.
At this pace his fore feet extend to a point perpendicularly below his nose, but they do not project beyond this line.

At a trot and bridled in, a horse throws his fore feet out beyond this line.

A canter is a much more artificial pace (Fig. 32). A horse is made to canter with sometimes one leg leading and sometimes the other. On a circle the horse is made to lead with the inside leg. The head is meanwhile drawn to the outer side, and the horse is urged with the outer leg. 


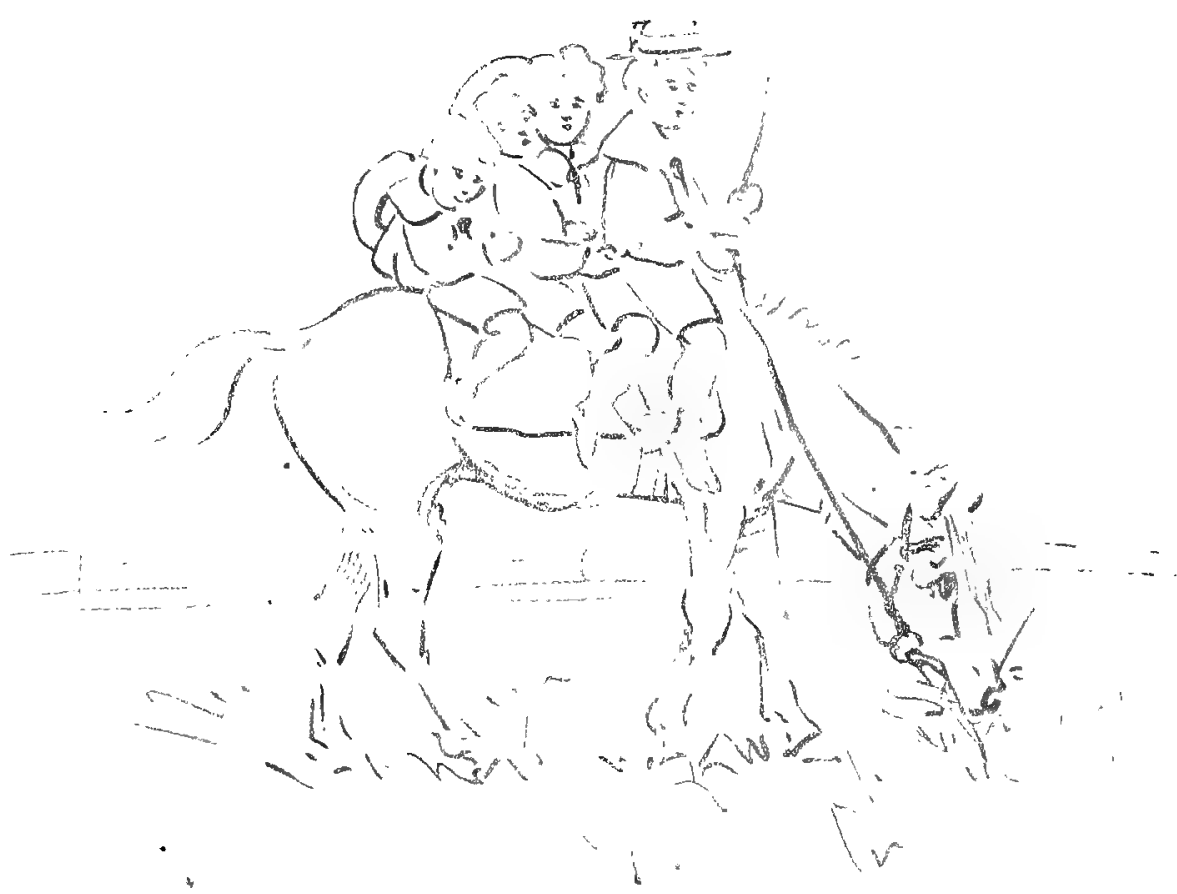

Fig. 31.-A Slow Wali.-Colonial Boys going to School.

Digitized by Microsoft [ 


\section{HINTS ON HORSES}

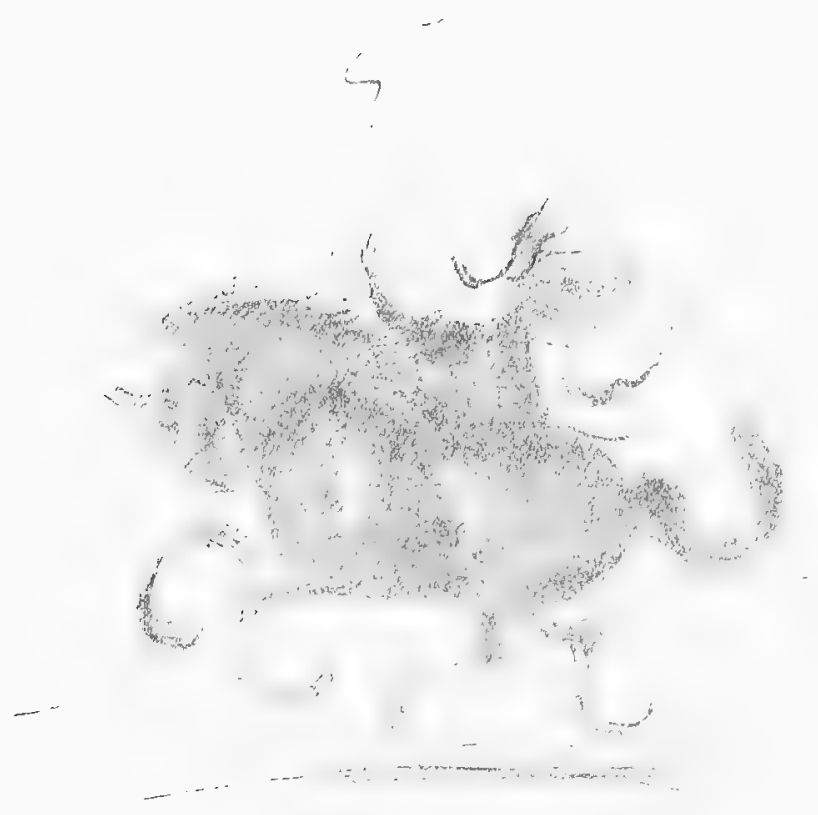

Fig. 32.-Colonial. Girls coning Home from Schooi..

Digitized by Microsoft $₫$ 
Peculiarities of movement. - Some horses in motion "braid," that is, cross their forefeet.
Some "dish," that is, throw their fore feet outwards. Some "brush," that is, strike their fetlocks, as already described.

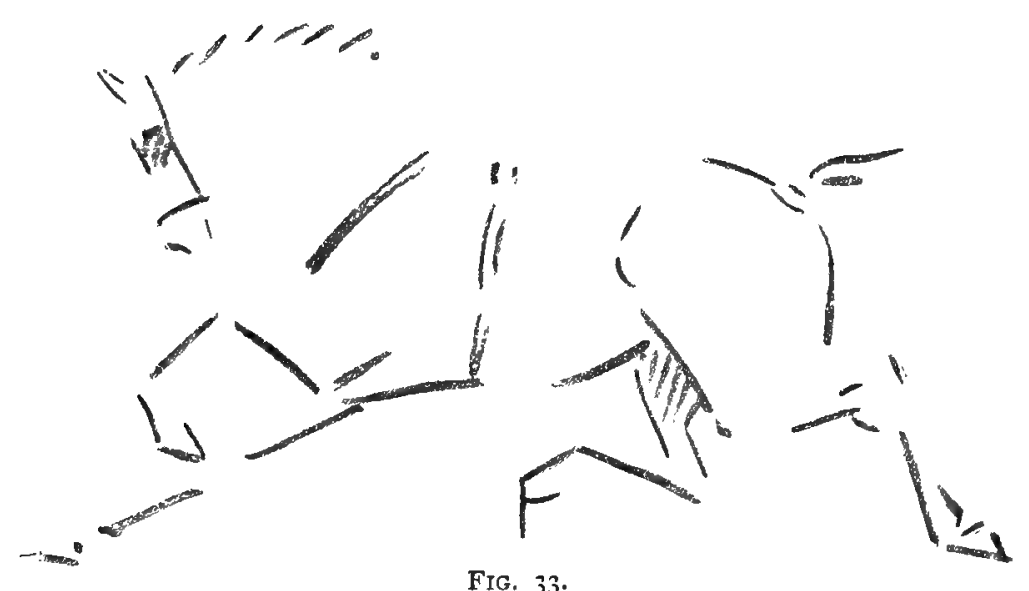

Some "speedy cut," i.e. strike thernselves just below the knee (Fig. 33) 
Some "forge," that is, strike the toe of the hind foot with the inside of the shoe of the forefoot on the same side (Fig. 34). very tired trot. It is therefore useful to remember this when depicting a tired horse.

On the other hand, he speedily cuts when

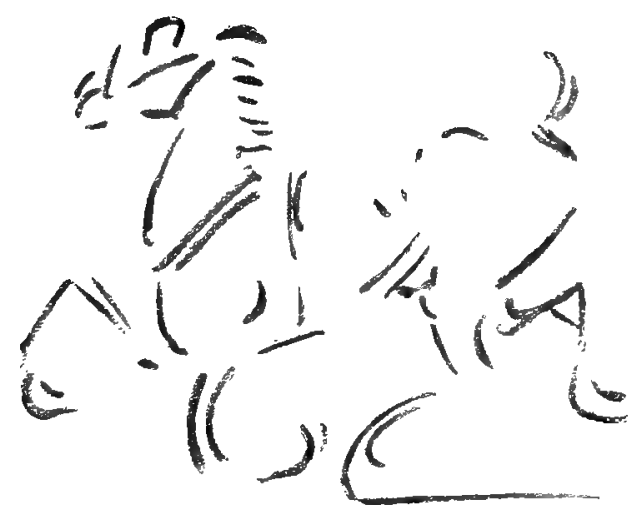

FIG. 34.

Some "over-reach," i.e. tread on the heel of the fore foot, with the toe of the hind foot on the same side.

The consideration of these peculiarities help a draughtsman to depict an animal in motion, since each of these movements is peculiar to some particular pace, and results in injury only when the animal over-exerts himself, e.g. a horse brushes at a walk or fresh and when trotting high and fast. $\mathrm{He}$ forges in his trot generally from weakness, or when in harness the weight behind him is too great.

A horse over-reaches in heavy ground or when jumping, especially bank jumping.

If we draw the legs so as just not to strike each other, then we shall produce the impression of the pace required. 
The lines of a horse in motion usually follow curves (Fig. 35),

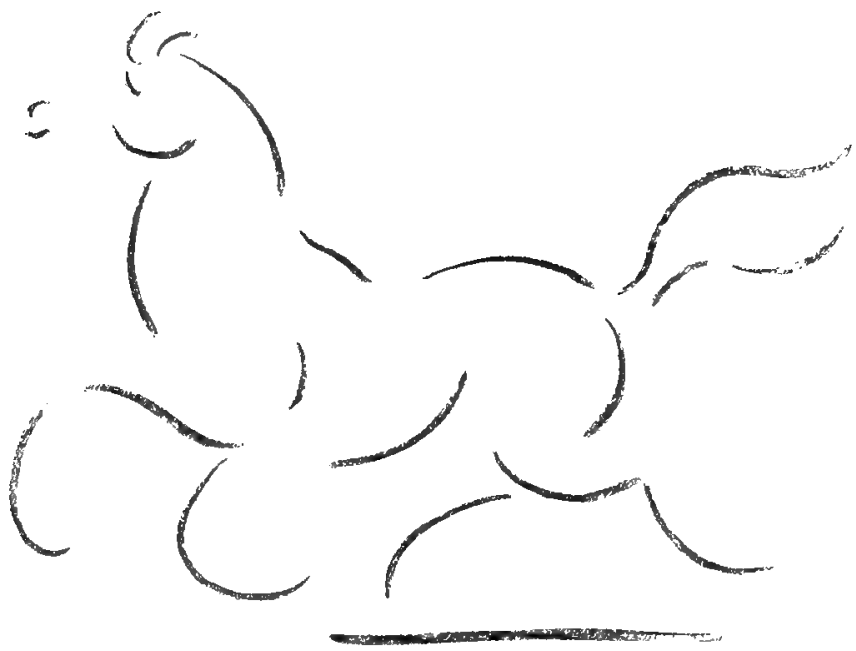

Fig. 35---Place a Coin on a piece of Paper and make a Conventional Trotter. 


\section{HINTS ON HORSES}

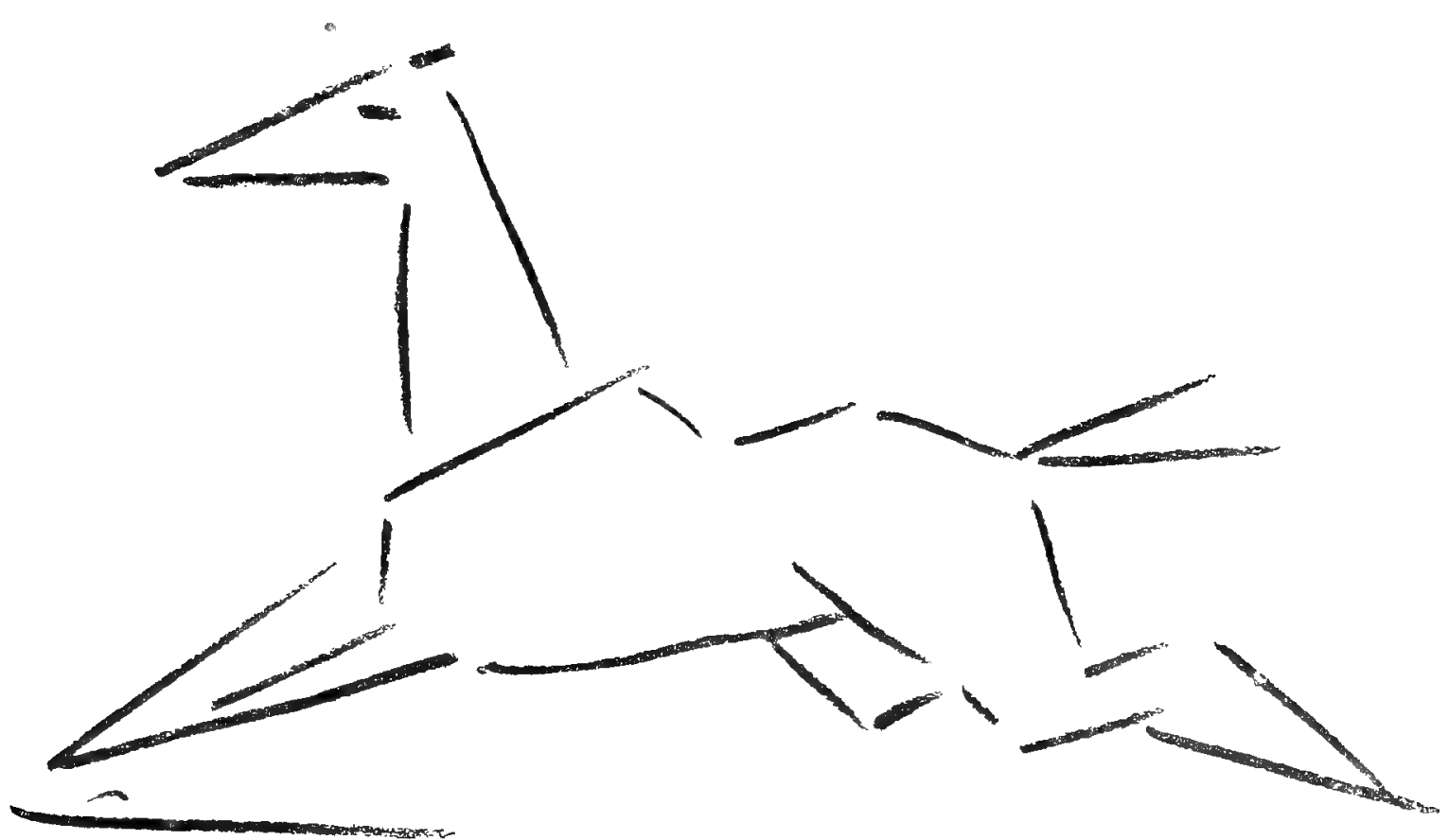

FIG. 36 .

and though there are some horses which are angular at all times in their movements, this rule may be considered generally to hold good (Fig. 36). 
The effect of motion depends to a certain extent on the manner in which surrounding objects are indicated. In watching a horse in motion the eyes are usually focused on him, consequently the spectator's head moves with the horse, and the surrounding objects appear to rush past him. The quicker the motion of the horse, the more indistinct they become. This effect may be produced by rendering the background somewhat indistinctly, and by the use of sweeping or horizontal lines (Fig. 37).

In drawing a galloping horse, if the lines representing the grass are drawn more hori- zontally than vertically, in a direction pointing in the opposite way from which the horse is going, and in sweeping strokes, they will help the horse to go. If, however, a few perpendicular blades of grass are introduced in front of the horse, the animal will appear to be trying to stop short or "prop."

The lines shading the horse should follow the direction of the movements desired. To suggest some quiet movement of one leg only, such leg would appear slightly indistinct; e.g. a horse, impatient for food, pawing; a horse lifting a hind leg whilst being groomed. 


\section{HIN'TS ON HORSES}

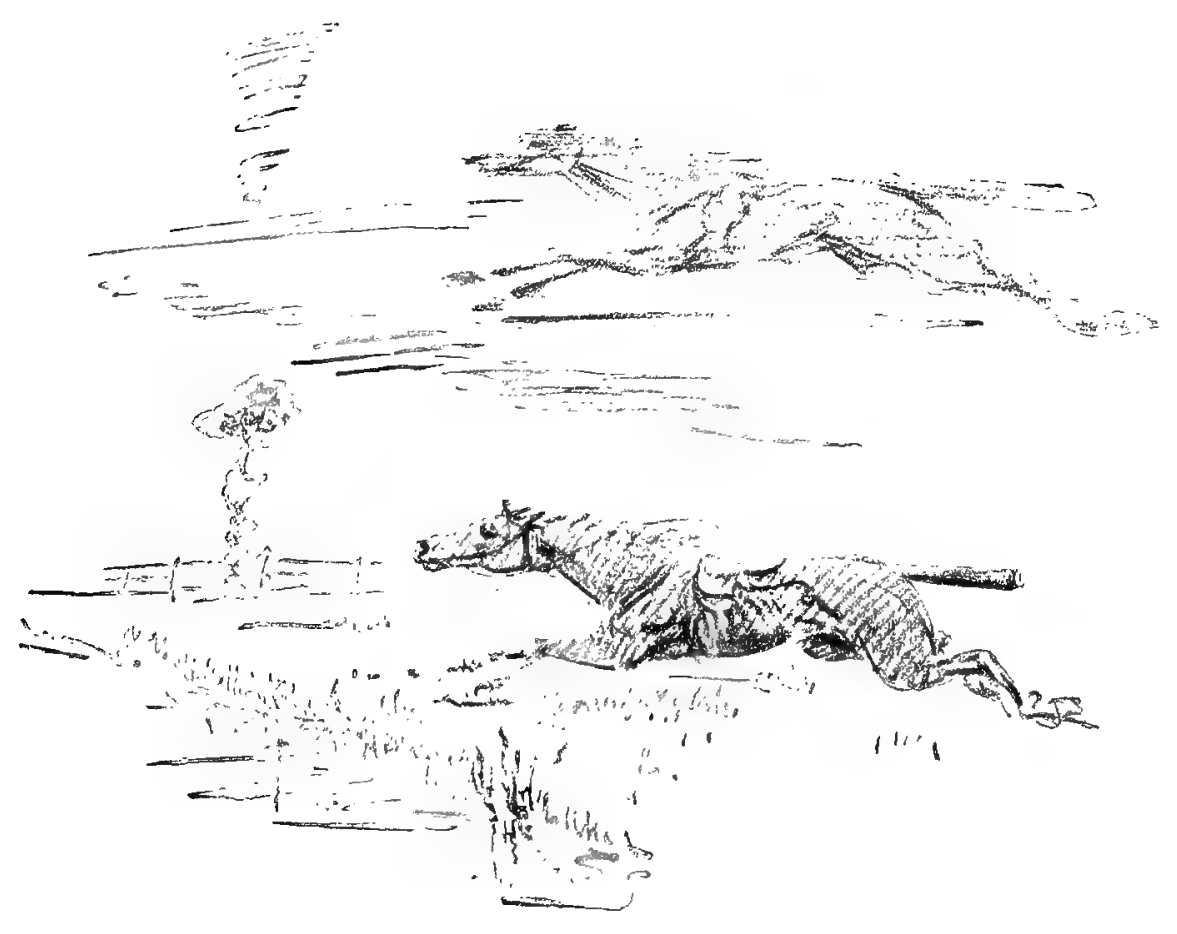

FIG. 37 . 
Terms of appreciation include-

Long in the rein.

Oblique clean-cut shoulder.

Muscular forearm.

Short below the knee, etc., etc.

Short back.

Tail well set on.

Hocks well let down.

"Stands over a lot of ground," etc., etc.
Terms of depreciation includeEwe neck.

Straight in front.

Slack loins.

Slab sides.

Long on the legs, etc., etc. 
To give an impression of the good points, and to eliminate the bad points, is the aim of the dealer, and also of the artist, if he wishes to make the most pleasing portrait.

A well-formed horse naturally stands over a lot of ground. If not so well formed, he is made to stand so as to give a good impression-a training carried to extremes in fancy harness horses. A man breaking a young horse may be seen gently tapping him behind the knees to make him advance his forelegs, at the same time forcing the head back with the bridle, the object being to give the shoulder the best appearance possible. Apparently the angle that a horse's forelegs make with his shoulder is practically the same in all horses, consequently a horse with an oblique shoulder stands with upright forelegs, whereas the horse with an upright shoulder must incline his forelegs backwards.

If this is so, to balance properly, the horse must advance his hind legs. As a result the ground covered by a straight-shouldered horse is small. A well-formed horse will easily learn to stand well. Not so a badly shaped one. The latter soon forgets his lessons, and, when the breaker is no longer with him, some people employ the gag and bearing rein. When a horse unnaturally stands over a lot of ground a deficiency must of needs show itself, and the slack-loined appearance of these straddled-out horses is the unpleasant result.

To make a mean-crouped horse carry his tail well, a padded crupper is resorted to. The object of disfiguring horses by docking their tails is to give the impression that the quarters are bigger than they really are. The reason for docking polo ponies is that, in playing a stroke far back, the stick may not be caught tight by the pony's tail. On the other hand, there are many good polo ponies with swish tails. Apart from the barbarity of the practice, an undocked polo pony is better able to twist and turn, and stop, to the requirements of the game. In support of this statement, notice the manner in which a greyhound gets the fullest value out of his tail, both as a rudder and a brake. 
Trimming, perhaps, requires a little notice, as by means of it the season of the year may be indicated.

Trimming is apt to take away from the natural beauty of the animal.

Hogging the mane is done to give a sharp appearance. It must be borne in mind that the head of a horse with a hogged mane looks too big.

Clipping, whole or partial, is resorted to to prevent the overheating of horses at exercise. Hunters often have the hair left under the saddle as extra protection to the back, and on the legs to minimize the discomfort of thorns, etc. A steeplechase horse is often clipped the same as a hunter, but a thoroughbred flat-racer is rarely clipped, and the extreme beauty of its summer coat is thereby enhanced. 


\section{HINTS ON HORSES}

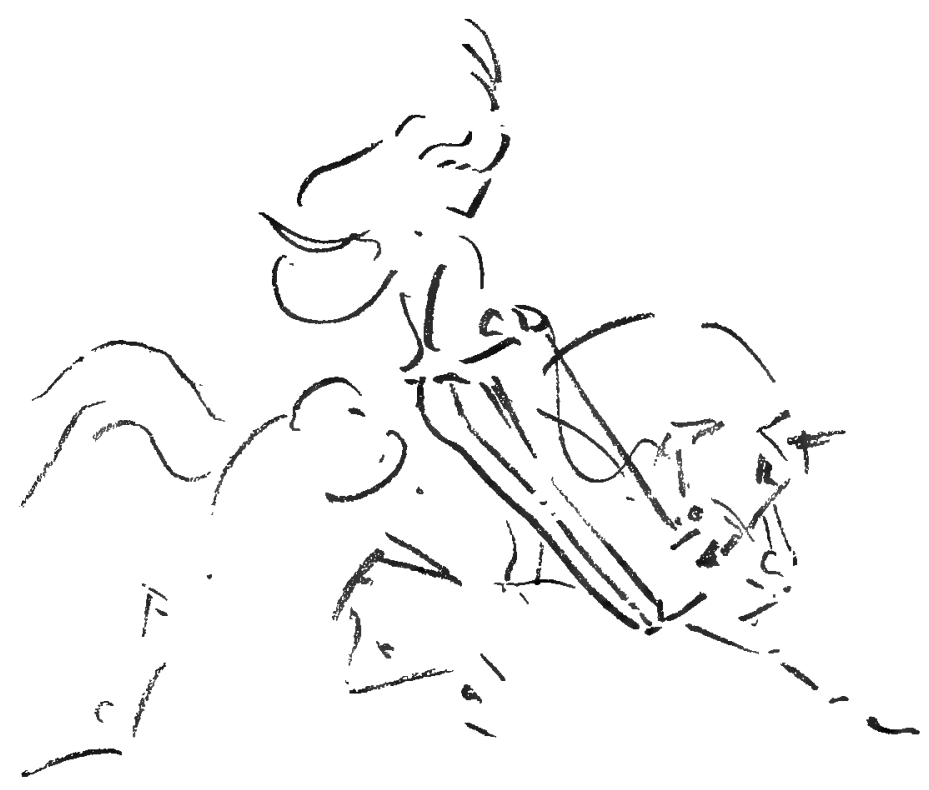

FIG. 38.

TiIe Rider.

The position of the rider varies from the old-fashioned straight-leg military seat (Fig. 38) to the crouched-up position introduced into Europe by the American flat-race jockey. 
A good rider does not ride more than his own weight. He sits down close to the saddle, and his thighs practically become part of the horse. He sways his body from the loins, conforming to the movements of the horse, so as to keep the centre of gravity of man and horse combined in the most suitable place.
E.g. in rising at a fence he leans slightly forward. The extra weight forward gives momentum. The relief of weight behind gives full opportunity to the propelling force of the hind-quarters. Whereas in descending to the ground he leans his body back, thereby allowing the forehand to alight without impediment. 
The steeper the ascent and descent, the further forward and backward does the rider swing. Compare the positions in jumping over a stone wall and a brook (Figs. 39 and 40). A bad rider, on the other hand, is loose in his seat. He adds to the fatigues of his horse by opposing his weight to the joint requirements of man and beast. He rides more than his own weight.

By his loose seat, when rising at a fence, he slips back, and would get left behind, were it not for the reins (Fig. 42). With these he jobs his horse in the mouth. The horse pulls him forward, and in the descent the rider finds himself again exactly wrong. $\mathrm{He}$ is no longer being left behind. He now precedes his horse (Fig. 4I).

From this it will be seen that a slip in taking off cannot be recovered, and a stumble, or peck, on landing in all probability results in a fall. Although jumping shows it up especially, the loose seat is in all paces a source of extra weariness and labour to the horse. 


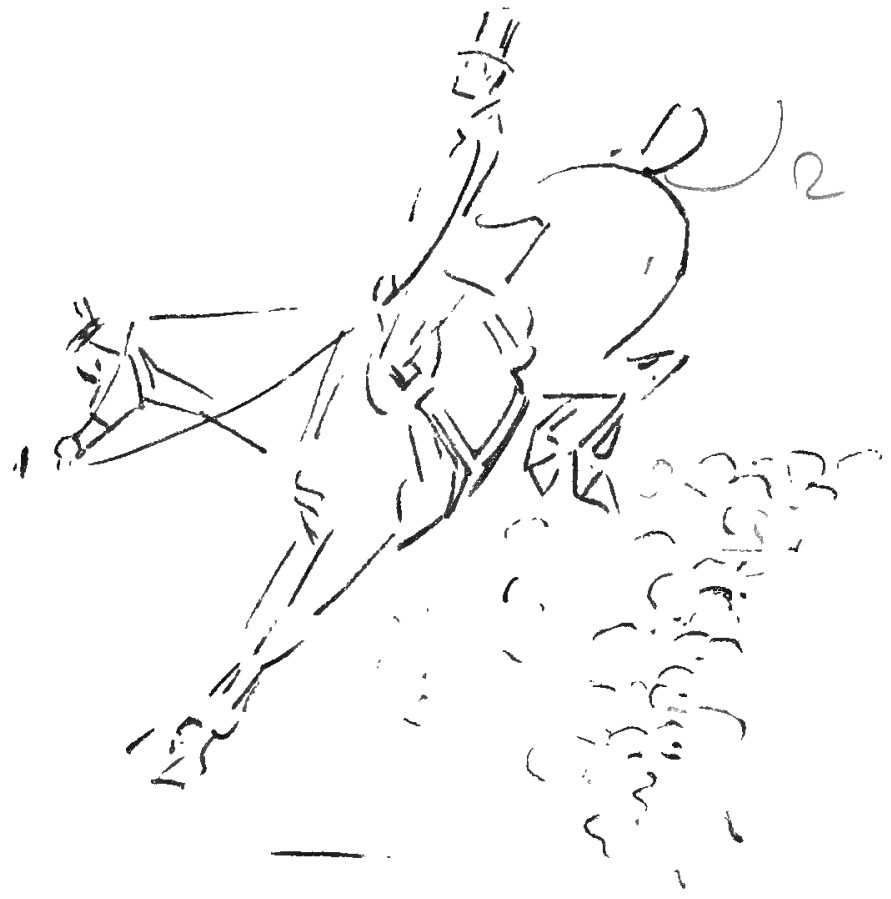

FIG. 39 .

Digitized by Microsoft [ 


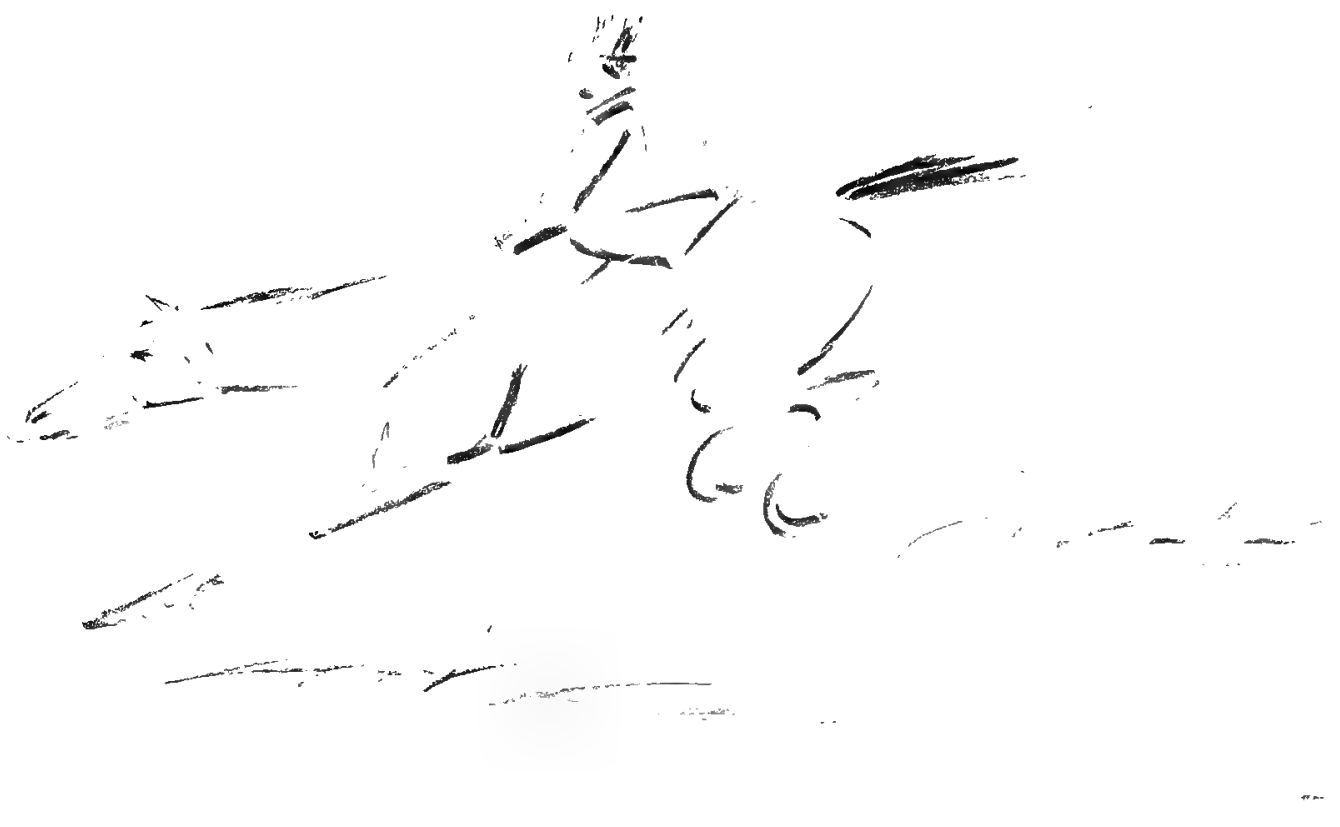

FrG, 40. 

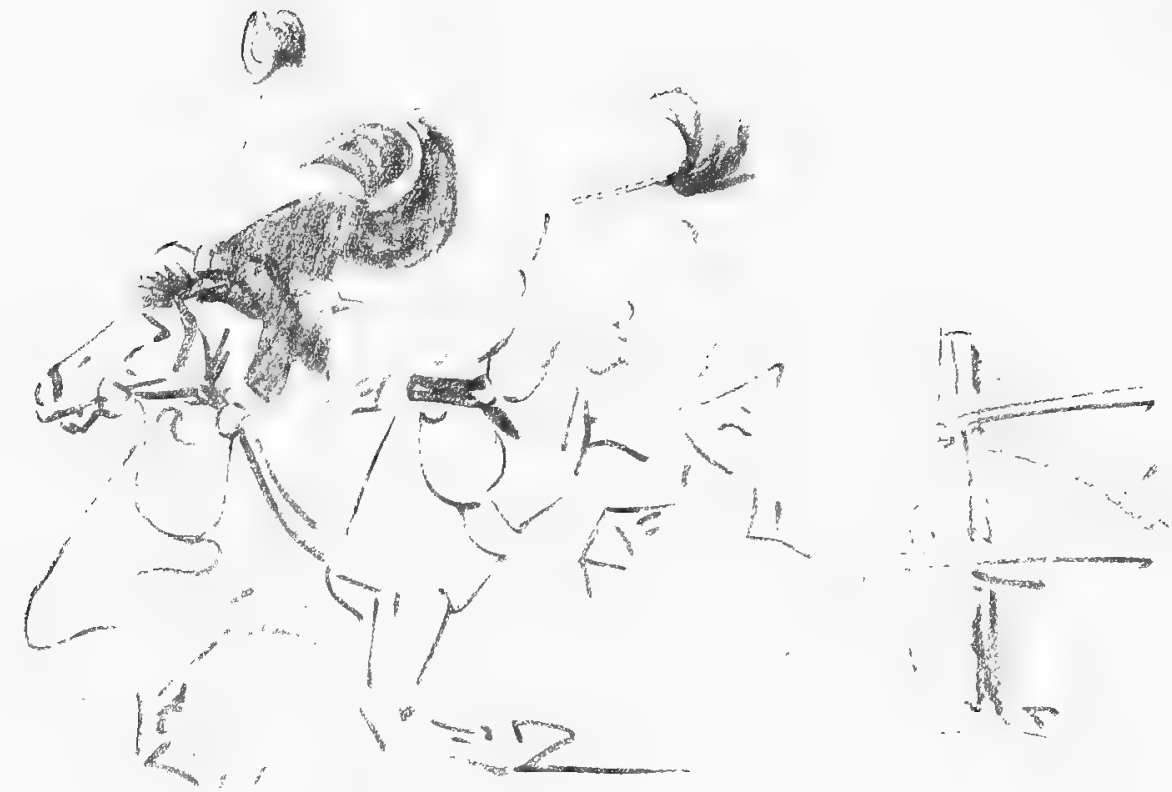

FIG. 41 .

Digitized by Microsoft $₫$ 


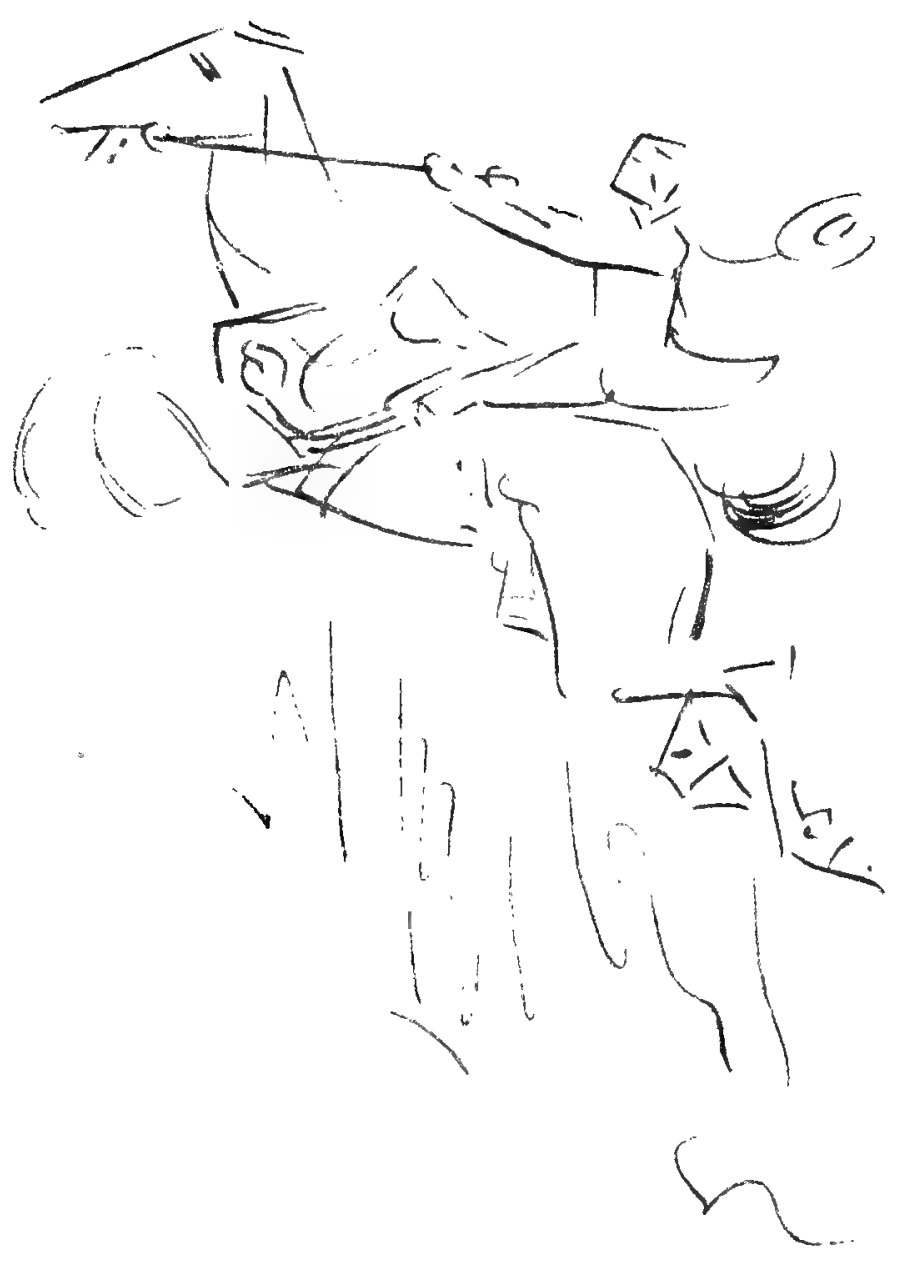

FIG, 42.

Digitized by Microsoft巴 
Apart from the manner in which a rider distributes his weight, the method of carrying out a journey on horseback may diminish or add to the fatigues of both man and beast. The rider should discover the peculiarities of his steed, e.g. a good-shouldered horse with sound fore legs can go downhill full speed without taking anything much out of himself. A straight-shouldered horse would be greatly jarred and distressed by attempting to do so. On the other hand, the straightshouldered horse might have the better wind, and might perform the journey at a steady pace uphill and down in exactly the same time as the oblique-shouldered horse, who would have to take it easy uphill, and make up for lost ground going downhill.

Some horses can keep up a steady trot the whole time with little fatigue, others prefer to vary their paces. To do the whole journey at a very slow pace is often much more wearisome to man and beast than to go at best pace all the way.

To tighten the girths after starting, without dismounting, often makes the saddle sit more comfortably. To slacken the girths after the horse has had a drink, in a similar manner, adds to the wellbeing of the horse (Fig. 43). 


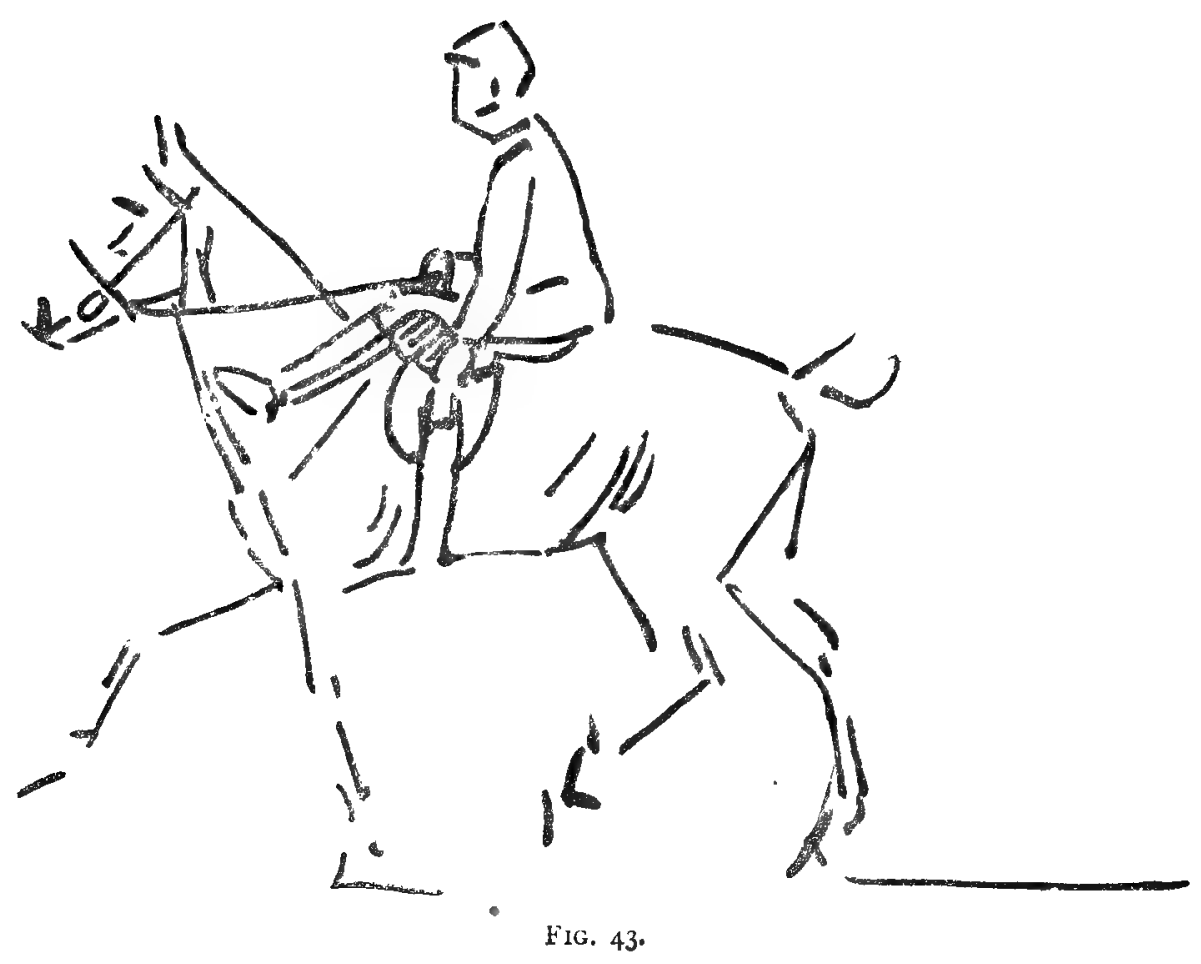

Digitized by Microsoft巴 


\section{SAdDLERY.}

The Marquis of Newcastle describes the saddles shown in Fig. 26 as the best. A very similar saddle can be easily made, on which to teach youngsters to ride.

Place a piece of numnah on the pony's back (Fig. 44). Seat the child thereon. Place the child's leg in the correct position, and with a piece of chalk draw on the numnah $(a)$ a line showing where the upper outline of the child's thigh will be. Then roll up a piece

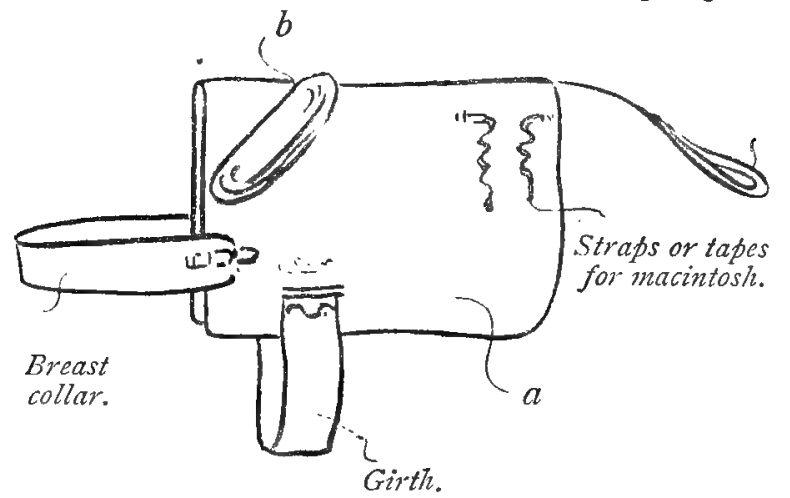

FIG. 44.

of blanket, cover it with soft leather or basil, and sew it to the numnah above and exactly following the chalk line (b). The child will derive great benefit from this "knee roll."
When the pony stops, instead of sliding forward on to the pony's withers, his thighs will be checked and kept in their proper place, and he will soon learn to grip with his legs correctly placed.

In training a youngster's pony it is often well to teach the animal to travel whilst you are level with his flanks, and not leading him by the head. With a small pony this is easily done. If you are walking on the near side of the pony lean your right arm over his loins, thereby forming a cantle as in the Marquis of Newcastle's saddle-hold a rein in each hand, and use your arms to keep him up in the same manner as you would use your legs. You will soon find the pony go up to his bit. Now, when you put up the youngster you will find the benefit. The child will be in front of you. Your right arm will be hugging the child, giving him confidence. With your two hands you will be able to place the child's thighs and knees in correct position, and teach him to grip. You will have the reins, and teach the child to acquire a seat before ever he has reins in his hands. This is the secret of good 


\section{HINTS ON HORSES}

hands. When you wish to trot or canter you can throw your weight on to the pony, and thus keep up easily with him. If anything happens, catch the child in your right arm, and whisk him off the pony's back.

With girls learning to ride on a side saddle they are at first inclined to "screw" at a trot, and not rise perpendicularly from the saddle. This screwing means sore backs, the animal's withers being wrung by the friction of the saddle. Make the child wear a Norfolk jacket having a pleat down the centre of the back, or chalk a straight line down the centre of her back, or else sew on a piece of ribbon, which can be easily noticed. The other children, or any one riding behind her, can then easily see and correct her if she is not rising truly.

The shapes of saddles correspond to the lines of a horse's shoulder. The flap cut forward corresponds to the oblique shoulder, and is the really comfortable shape (Fig. 45). It gives ample room for the thigh to grip the whole way along $(a b)$. A straight-cut saddle and an upright shoulder correspond to each other (Fig. 46). The room from the point of the flap to the cantle is obviously shorter $\left(a^{\prime} b^{\prime}\right)$, and

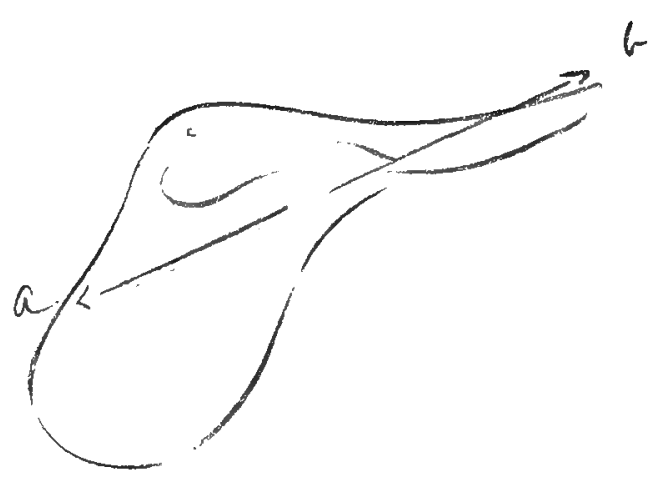

FIG. 45.

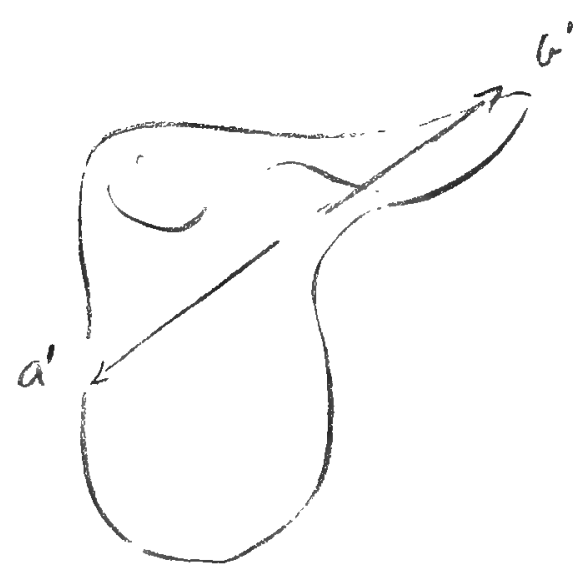

FIG. $4^{6}$. 
in consequence reduces the comfort of the seat. Knee rolls are a matter of individual preference.

Ladies' saddles follow the same principles, and should be cut so that the crutch comes over the centre of the thigh and does not press on the point of the knee. The number of crutches, pommels, etc., are a matter of individual taste.

A saddle-horse with a good shoulder carries the girth well clear of the movements of the elbow. The straighter the shoulder the more forward does the girth sit, the tendency being to cause a gall.

A grass-fed horse often chafes, as the full barrel forces the girth right under the elbow. Hence in Colonial towns horses may be seen with the girths round their necks, like a collar, to prevent the saddle riding back, and a crupper under their tails to prevent its moving forward (Fig. 47). The difficulty is in mounting not to dislodge the saddle. Once up it is easy enough to keep the gear in position. 


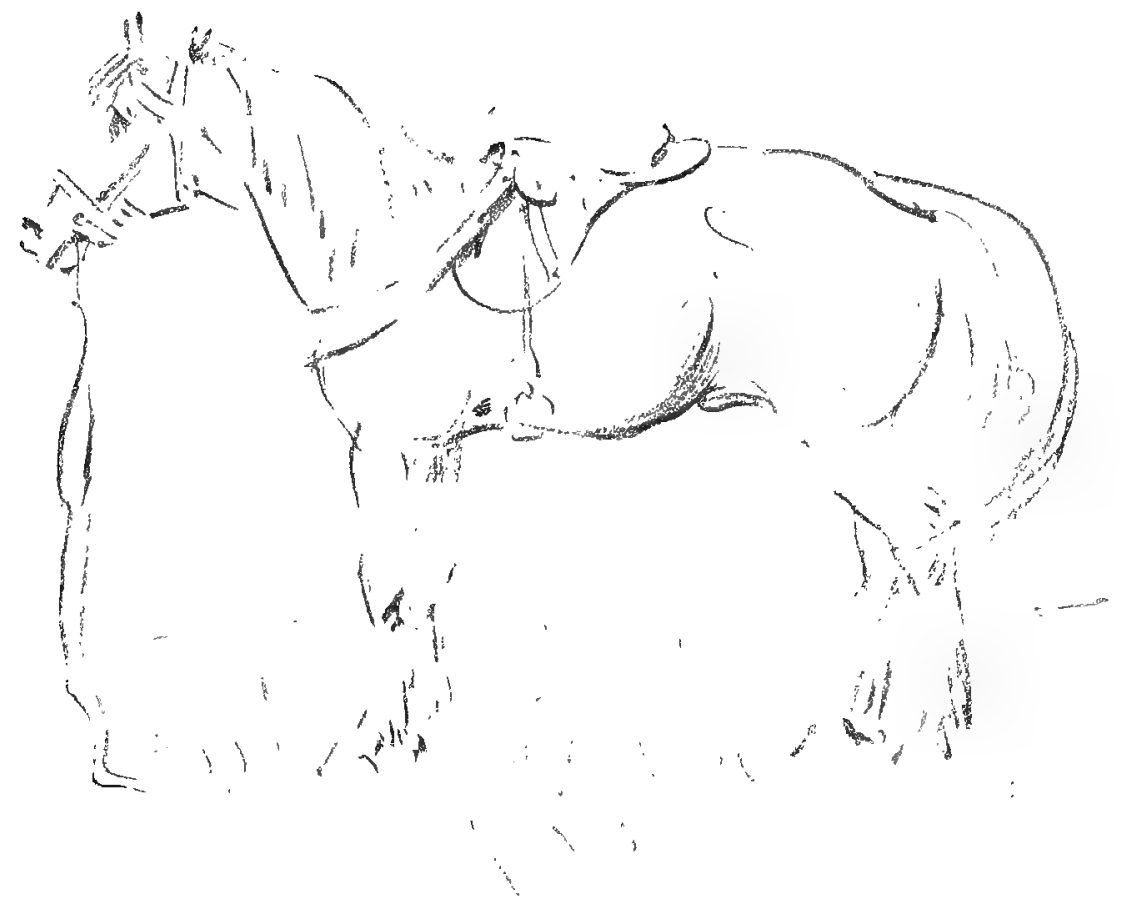

FIG. 47.

Digitized by Microsoft $\circledast$ 
Bridles vary greatly, from plain snaffles to double bridles, of which there are many varieties. An ordinary "Pelham" bit is a mixture of the two. Without the curb chain it is practically a snaffle, and with the curb chain a double bridle. It requires less leatherwork than a double bridle, and is possibly the simplest bit for all-round use.

\section{Driving.}

$\Lambda$ mongst coachmen we notice two methods, the one showing the compact position which inspires confidence, and the other the loose method which suggests a great element of chance (Fig. 48).

If the wrist of the left or driving hand is kept supple and bent, the back of the hand will be at an angle to the forearm.

The reins follow more or less the line of the forearm. It will be seen that the strength of the back of the hand is added to the strength of the fingers in taking the strain of the horses. Now, if the wrist is unbent, and the forearm and back of the hand form one continuous line, the whole pull comes on the fingers, the reins soon slip, and the feeling of confidence gradually vanishes.

The elbow must be kept to the side, sticking it out will do no good. 


\section{HINTS ON HORSES}

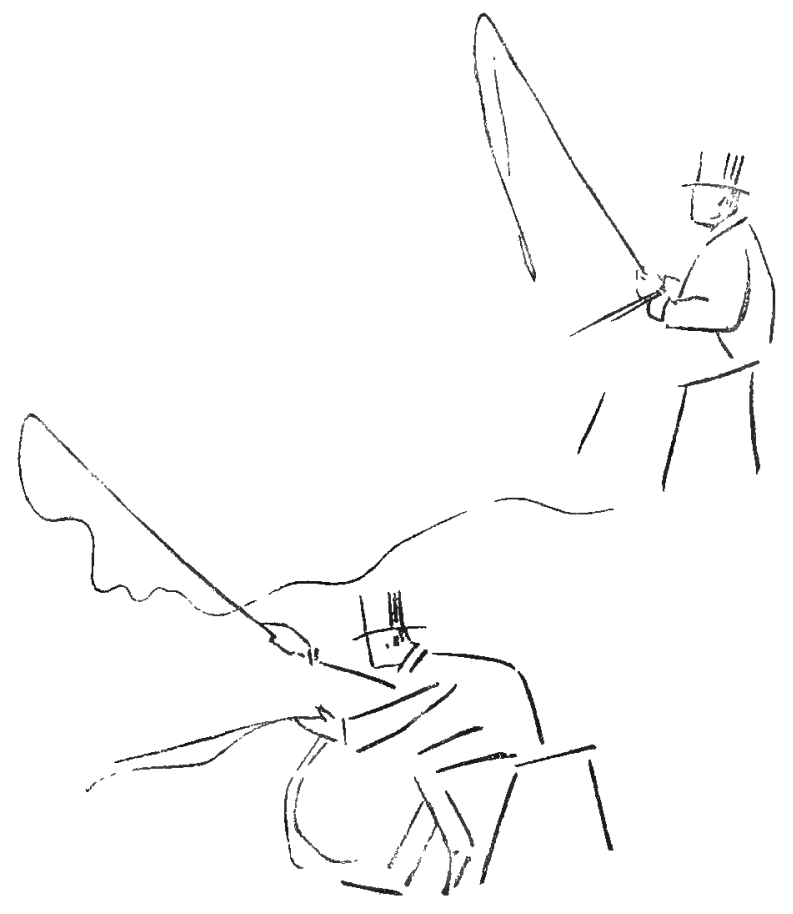

FIG. 48.

Digitized by Microsoft $₫$ 
The manner in which a horse stretches his harness is, after all, the chief criterion by which a driver may be judged.

In single harness there is not much to note. Should, however, a horse appear coming downhill with tight traces, it may be safely assumed that the pace will keep increasing, and the difficulty of clearing an obstacle at the bottom be considerable.

With a pair, if the horses are equally strong, each horse should do his fair share of the work.

In breaking a young horse, it will be noticed that the old stager, who is put in to convey his experience to the beginner, does all the work of starting, but as soon as the pupil begins to feel the collar, the old hand gradually hangs back, until eventually his traces are quite slack.

In sketching a team, note two things, the reins and the traces.

In starting, if the leaders stretch their traces first (Fig. 49), they will pull the coach on to the wheelers, who will promptly hang back as if going downhill. The driver will pull on the reins to stop the leaders; but the leaders' reins being too long, he will still further pull the wheelers back, without, perhaps, ever getting a proper feel of the leaders' mouths.

The weight on the leaders' shoulders will then become too much for them, and they may jib or rear. In any case, for some time the drive will be thoroughly uncomfortable. 


\section{HINTS ON HORSES}

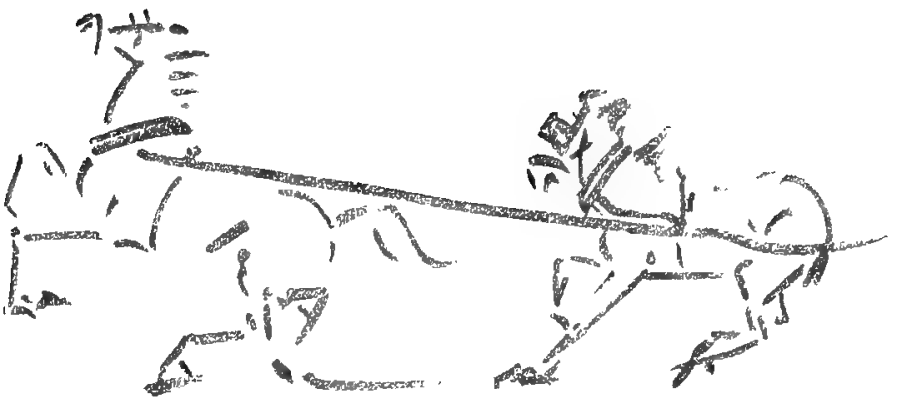

FIG. 49.

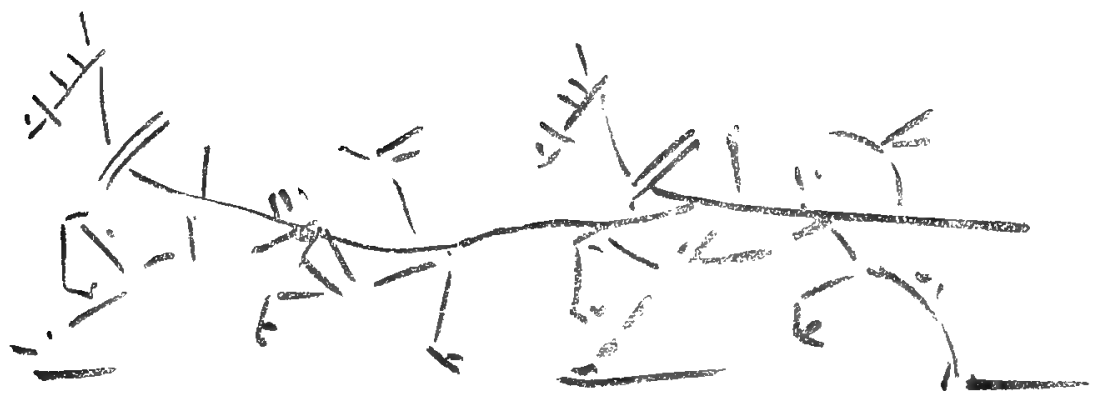

FIG. 50.

Therefore, if a coachman be depicted starting his team, the wheelers' traces should be made tight, their reins just loose, the leaders tight on the rein and slack on the trace (Fig. 50).

\section{Digitized by Microsoft巴}


Uphill traces should all be taut.

Downhill the reverse.

In a tandem notice the same points.

If the team is coming round a corner place the whip in the coachman's hand as if ready for immediate use on either wheeler. If the wheelers are cutting the corner too fine, a touch on the inside horse will send him up to the front, and force the point of the pole outwards. If not coming round sharp enough, a touch on the outside horse will swing the pole inwards.

In coming round a corner the hind wheels will travel on a smaller circle than the front wheels, so care must be taken to leave enough road on the inside of the inside front wheel for the hind wheel, unless the draughtsman desires to suggest that the coach is about to foul the corner.

In some countries it is the custom to drive teams of six, eight, or ten mules or horses from the box (Fig. 5I). At first it appears as if no man could be strong enough, but if the relations which traces and reins bear to each other be noticed, the solution of the difficulty will be discovered. 

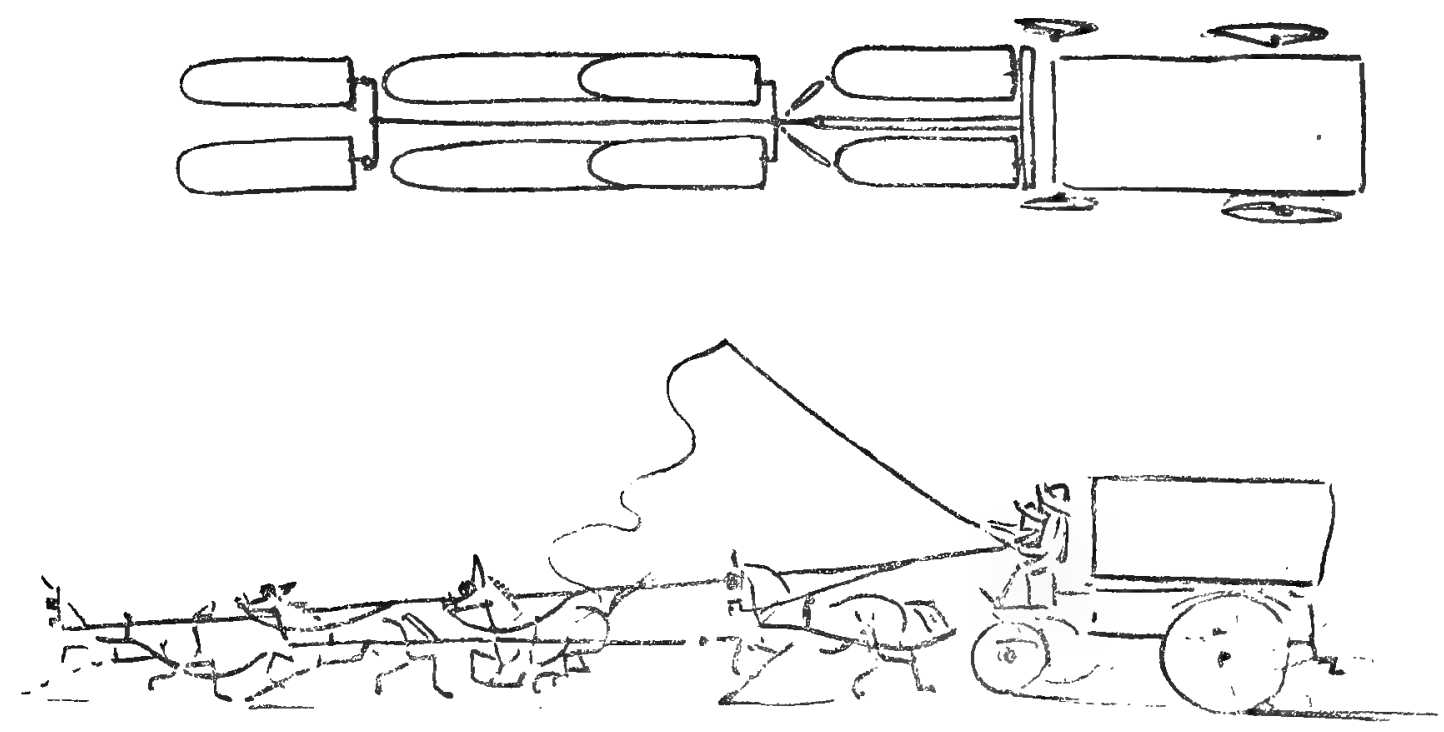

FIG. 5I.

In Figure $5 \mathrm{I}$ it will be seen that the leaders have taut reins and slack traces, the central pairs the reverse, and that the wheelers are as any ordinary pair. 
The leaders pull on the driver's hand through the reins, and owing to their seldom being in the collar they keep fresh and act as pacers to the team.

The central pairs strain after the leaders, but the weight is thrust on the carriage through the traces, and not on the coachman's hand. Consequently he need exert no greater strength in piloting a properly harnessed team of ten than a team of four.

With these big teams a longer and heavier whip than an ordinary four-horse whip is required. A second man, as a rule, sits on the box beside the coachman with the reins. This man is generally possessed of great skill, and keeps all the laggards of the team up to their work.

In drawing a coach, it is quite worth paying attention to the coachman's whip. A wellcaught-up loop looks workmanlike. A big loop halfway down the stock looks slovenly, and one knows that it will soon come down altogether. A long flying lash, unless the coachman is striking the leaders, is quite absurd. If the wheelers are being touched with the whip, it should be with the double thong of the loop of the whip. There is one stroke in which the professional Jehu strikes all four horses in succession with the single thong in one backward and forward sweeping stroke.

The driver catches the thong on the stock of the whip close above his hand, and lets it fall under his thumb. He then with a figureof-eight movement loops the thong. In windy weather he often catches the thong on his forearm.

He holds the whip-handle near the upper collar, his hand being a few inches up from the butt. This balances the whip in his hand.

Some whips are bent in the stock. This allows the rain to drip off in wet weather without running into the driver's hand. Notice also the indiarubber ring on 'busdrivers' whips for a similar purpose. 


\section{HINTS ON HORSES}

The harness consists of bridle, collar, traces' pad, and breeching (Fig. 52).

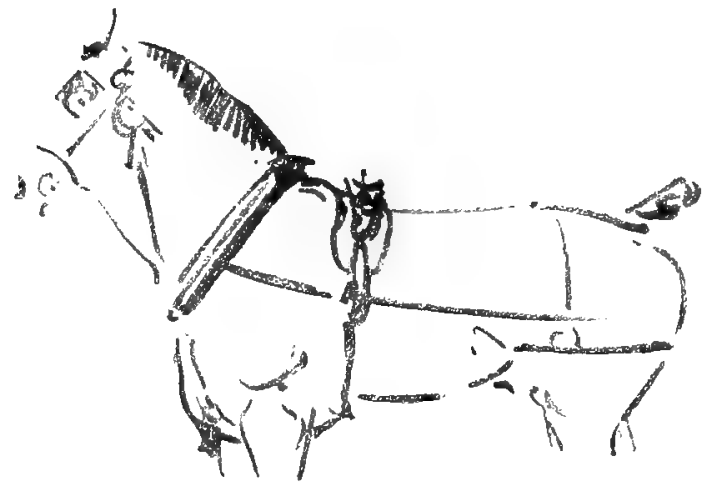

FIG. 52.

'Bus-horses wear bridle, collar, and traces only.

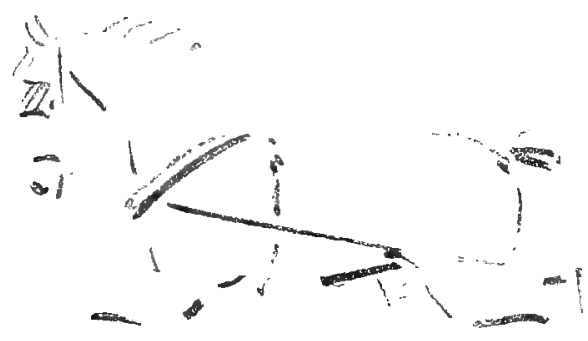

FIG. 53.

The breeching is often omitted, and rarely seen in light double harness (Fig. 53).

If we place the harness correctly on a piece of paper, it is very easy with a line or two to suggest the horse. The angle of the collar will give the character of the horse.

\section{Digitized by Microsoft巴}




\section{Buying at Auction.}

To those wishing to buy a low-priced horse, auctions offer the greatest opportunity. When attending an auction, method means saving time, and keeping your head clear. I recommend that first of all the catalogue should be read right through. Scratch out all unsuitable lots, using some hieroglyphic, as it is just as well that people looking over your shoulder should have no idea whatever of the meaning of your notes. Now study the possible lots, and make marks by which you will readily note any that are partially or wholly "warranted." For these you will be able to give your full price, because, if they do not fulfil the warranty, you can return them within a certain time, specified on the conditions of sale. The unwarranted ones you buy at your own risk, and their price should accordingly be less. It does not necessarily follow because a lot is termed unwarranted that unsoundness is implied; on the contrary, horses included in sales by order of executors, etc., are often unwarranted, but may be first rate. Having thus got your catalogue intelligible to yourself, and quite handy, get hold of a "runner," and with him walk right round the stables. Tell him what you want. He will probably be able to tell you of any horses that have a reserve price, or are likely to make money. You will then be able hieroglyphically to remove them from your list if they are certain to be more than your price. It is no good to spoil your eye by looking at horses which are beyond your figure. Doing so will often put you off the useful horses which may be exactly what you want.

Your own list has thus been cut down to the possible choices. To this you must add any that your runner suggests to you. Now proceed to look at each horse on this final list. If the horse takes your fancy, before running him out lift up his feet. If they are nasty, or shod in a suspicious manner, remember "no foot no hoss." If the feet satisfy you, proceed to look for blemishes, which signify faulty action, such as brushing, speedy cutting, etc. If these exist, bear in mind that they can be counteracted, but it may be necessary for the 
horse to wear a shield or guard. Such a necessity reduces the value of the steed. Now get your runner to open the horse's mouth, and form your opinion as to whether his age is suitable. If so, have the horse run out. In the open you can quickly note his proportions-slope of shoulder, length of back, carriage of tail, depth of girth, form and condition of legs. Look at the horse all round, and if you fancy him at all, have him trotted up and down. Then make your hieroglyphic note, denoting whether the animal is worth your full price, or whether he would do at a bargain price. If unsuitable, scratch him off. In this manner, before long, you will find only a few "possibles" left. Run these out again, but do not confine yourself only to one or two, as you may thereby give yourself away as to which you fancy.

The difficulty now arises in the order in which the lots will be put up for sale. Your first choice may be the first of the "possibles," in which case you can bid comfortably up to your limit. On the other hand, your pet selection may be low down, and you will have to use your own judgment. The tendency is to diminish your bids for the earlier lots. If you have failed to buy, and the last "possible" is up for sale, remember that if you fail to suit yourself you will have to reckon your out-ofpocket expenses as dead loss, and, consequently, it may be worth your while to raise your bids slightly. If you fail to buy, your runner will be able, very often, to find out if any of your lots were unsold, and are for disposal by private treaty. In this case you would probably have to pay more, but for the extra you would get a thorough trial. If you have bought a horse, try him, to see if he fulfils his warranty, and notify in plenty of time if you wish to return the animal. If he carries out his requirements you are fitted up with a horse at market price. If after a bit you don't care for the beast, you have every reason to expect to get market price back again for him; but do not send him straight back to the yard from which you bought him. Horses that are constantly changing hands become known, and are avoided. The market price of horses varies with the season, e.g. if you want a harness horse for the summer, buy a hunter, which is quiet in harness, at the end of the

\section{Digitized by Microsoft@}


hunting season, and send him up warranted for the sales at the beginning of the next season. The difference in market price should cover your sale expenses, and quite possibly, partially or completely, pay the summer's forage bill.

\section{Tethering.}

To teach horses to stand on the veldt, Boers throw the reins over their horses' heads, and allow them to trail on the ground with a weight attached.

The horse is unable to drag this weight, and is therefore practically tethered.

By degrees the weight is reduced, and eventually the horse learns to stand still as soon as the reins are thrown over his head.

The trainer who teaches his horse to follow him, always leaves the reins lying on the saddle. As a result, if the rider wishes to go on foot, with his horse following, he merely jumps off and walks ahead. If, however, he wishes to move away on foot alone, he throws the reins over the horse's head.

For an untrained horse the following method may often be found of service :-

Attach a spring hook to the ring of the bit, the snaffle for choice, otherwise to some convenient portion of the bridle. On dismounting draw the horse's head round towards its flank, and snap the spring-hook on to the stirrup iron.

In the cases of a long man on a little pony, or a short man on a big horse, the stirrupleather will be found either too long or too short. Under such circumstances an ordinary chain, or leather dog-lead, attached to a $\mathrm{D}$ just behind the flap of the saddle will meet the case. Thus fastened, the horse cannot stampede, but the position being very cramped, the scheme should only be resorted to during short periods of urgency.

To tether groups of horses the Italians have a good way of attaching the head-ropes of several horses to a small iron wheel, with about four spokes.

Horses thus tethered must bunch together with their heads inwards, consequently if they attempted to proceed in any one direction a certain proportion of them would have to move backwards.

\section{Digitized by Microsoft巴}


Stampeding en masse, therefore, with this method, is practically impossible, and the wheel (unlike the peg) being unattached to the ground, individual horses are unable to get a direct pull against it, with a view to break their head-gear, a trick which many horses acquire, and are in consequence tied up with a thick strap round the neck like a dog-collar.

When thus tethered to a ring, the horses are fed in groups, but without nosebags it is impossible to insure that each horse gets his fair share of grub.

A wheel of about eight inches diameter will hold twelve or thirteen horses. A quoit of about this size, with holes drilled through it, might make a convenient tethering ring. The head ropes would be passed through the holes and then knotted, to prevent the horses getting free.

The method of tethering to long picket ropes has its advantages in moving a large body of animals across country. The ropes are invaluable for the passage of rivers. If a herd of horses is driven into a river, it is with difficulty that they can be forced to land at any given point. The tendency is for them to scatter, some up, some down stream, and to land at various points on either bank, or, if there be one, on an island.

By attaching the ropes together, passing one end across the stream, and retaining the other, a form of ferry is established. To this rope the horses should be tethered, as if in camp, and then dragged across the river in groups. By this means the horses will be landed in their proper order, and no delay need arise due to sorting them, etc. The number of horses in each group depends on the length of the rope, which must be more than twice as long as the width of the stream. The rope must always be kept taut, and not allowed to sag below the water, otherwise it is apt to foul the animals' legs, and prevent their swimming. In which case animals often blow themselves out like bladders, and though they can be dragged ashore and saved, the difficulty of disentanglement and risk of injury is great.

After the passage of the animals, the rope can be rigged as a tight rope for the dry passage of gear.

\section{Digitized by Microsoft@}


A tethering quoit made in alumin would compare favourably as regards weight with twelve picketing pegs.

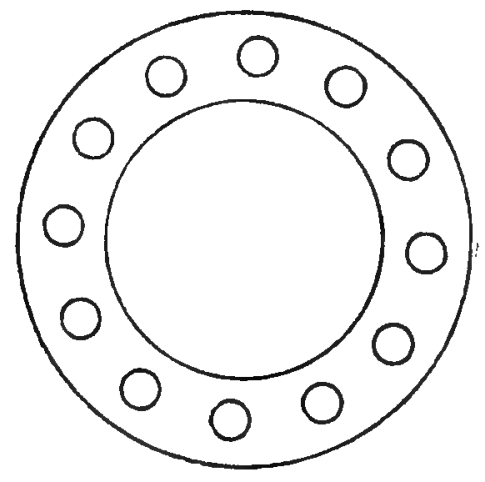

FIG. 54.

THE END 


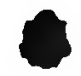

Digitized by Microsoft巴 
Digitized by Microsoft巴 
Digitized by Microsoft巴 
- 